\title{
Probabilistic Forecast for Twenty-First-Century Climate Based on Uncertainties in Emissions (Without Policy) and Climate Parameters
}

\author{
A. P. Sokolov, P. H. Stone, C. E. Forest, ${ }^{*}$ R. Prinn, M. C. SArofim, ${ }^{+}$M. Webster, \\ S. PAltsev, ANd C. A. Schlosser \\ Joint Program on the Science and Policy of Global Change, Massachusetts Institute of Technology, Cambridge, Massachusetts

\section{KICKLIGHTER} \\ The Ecosystems Center, Marine Biological Laboratory, Woods Hole, Massachusetts

\section{S. DutKiewicZ, J. ReILly, AND C. WANG} \\ Joint Program on the Science and Policy of Global Change, Massachusetts Institute of Technology, Cambridge, Massachusetts

$$
\text { B. FELZER }{ }^{@} \text { AND J. M. MELILLO }
$$ \\ The Ecosystems Center, Marine Biological Laboratory, Woods Hole, Massachusetts \\ H. D. JACOBY \\ Joint Program on the Science and Policy of Global Change, Massachusetts Institute of Technology, Cambridge, Massachusetts
}

(Manuscript received 29 September 2008, in final form 19 March 2009)

\begin{abstract}
The Massachusetts Institute of Technology (MIT) Integrated Global System Model is used to make probabilistic projections of climate change from 1861 to 2100 . Since the model's first projections were published in 2003, substantial improvements have been made to the model, and improved estimates of the probability distributions of uncertain input parameters have become available. The new projections are considerably warmer than the 2003 projections; for example, the median surface warming in 2091-2100 is $5.1^{\circ} \mathrm{C}$ compared to $2.4^{\circ} \mathrm{C}$ in the earlier study. Many changes contribute to the stronger warming; among the more important ones are taking into account the cooling in the second half of the twentieth century due to volcanic eruptions for input parameter estimation and a more sophisticated method for projecting gross domestic product (GDP) growth, which eliminated many low-emission scenarios.

However, if recently published data, suggesting stronger twentieth-century ocean warming, are used to determine the input climate parameters, the median projected warming at the end of the twenty-first century is only $4.1^{\circ} \mathrm{C}$. Nevertheless, all ensembles of the simulations discussed here produce a much smaller probability of warming less than $2.4^{\circ} \mathrm{C}$ than implied by the lower bound of the Intergovernmental Panel on Climate Change (IPCC) Fourth Assessment Report (AR4) projected likely range for the A1FI scenario, which has forcing very similar to the median projection in this study. The probability distribution for the surface warming produced by this analysis is more symmetric than the distribution assumed by the IPCC because of a different feedback between the
\end{abstract}

\footnotetext{
* Current affiliation: Department of Meteorology, The Pennsylvania State University, University Park, Pennsylvania.

${ }^{+}$AAAS Science and Technology Policy Fellow, Washington, D.C.

\# Current affiliation: Engineering Systems Division, Massachusetts Institute of Technology, Cambridge, Massachusetts. @ Current affiliation: Department of Earth and Environmental Sciences, Lehigh University, Bethlehem, Pennsylvania.
}

Corresponding author address: Andrei Sokolov, Joint Program on the Science and Policy of Global Change, Massachusetts Institute of Technology, 77 Massachusetts Ave., E40-431, Cambridge, MA 02139.

E-mail:sokolov@mit.edu 
climate and the carbon cycle, resulting from the inclusion in this model of the carbon-nitrogen interaction in the terrestrial ecosystem.

\section{Introduction}

Projections of anthropogenic global warming have from the start been confounded by the many economic and scientific uncertainties that affect forecasts of anthropogenic emissions and the response of the climate system to these emissions (e.g., Houghton et al. 2001; Solomon et al. 2007). Up until 2001, the uncertainties in the projected climate changes were generally dealt with by giving ranges of projected changes but without any likelihoods being associated with these ranges. Such projections leave it to the nonexpert reader to assign probabilities to the possible outcomes; Moss and Schneider (2000) advocated that projections should be given in probabilistic terms to provide more complete information.

Subsequently, considerable effort has been devoted to quantifying the scientific uncertainties associated with climate model projections for a given forcing scenario. Most notably the latest Intergovernmental Panel on Climate Change (IPCC) report (Meehl et al. 2007a) attempted to do this for the six Special Report on Emissions Scenarios (SRES) scenarios (Nakicenovic et al. 2000) using a variety of coupled atmosphere-ocean general circulation models (AOGCMs) and models of intermediate complexity. These projections and different sources of uncertainty have been reviewed by Knutti et al. (2008).

While formal uncertainty analysis of emissions projections was investigated a couple of decades ago (e.g., Nordhaus and Yohe 1983; Edmonds and Reilly 1985; Reilly et al. 1987) it was largely ignored by the scientific community. The IPCC SRES process eschewed formal uncertainty analysis of emissions in favor of scenario analysis (Nakicenovic et al. 2000). Despite clear statements to the contrary (Nakicenovic et al. 2000), there have been attempts in the literature to interpret the SRES scenarios in a probabilistic or quasi-probabilistic sense to investigate the joint effects of uncertainty in emissions and climate outcomes (e.g., Wigley and Raper 2001). In the latest IPCC report uncertainty ranges for possible climate changes are given separately for different SRES scenarios and reflect only uncertainty in climate system response (Meehl et al. 2007a). In contrast, our approach allows us to combine uncertainties in emissions and in climate system characteristics.

The most comprehensive formal treatment of both emissions and scientific uncertainties to date is that of Webster et al. (2003). In that work, uncertainty in emissions projections was driven by uncertainty in future eco- nomic growth and technological change (Webster et al. 2002) as well as uncertainty in current levels of emissions (Olivier and Berdowski 2001). The climate system uncertainties were quantified from an analysis of observed twentieth-century temperature changes (Forest et al. 2002).

In this paper, we update the Webster et al. (2003) probabilistic projections of climate change from the present to 2100. The Webster et al. (2003) used the Massachusetts Institute of Technology (MIT) Integrated Global System Model (IGSM; Prinn et al. 1999), which couples an economic component [the MIT Emissions Prediction and Policy Analysis Model (EPPA); Babiker et al. 2001] to a climate model of intermediate complexity (Sokolov and Stone 1998; Wang et al. 1998).

The IGSM was designed to be flexible and numerically efficient and so is well suited for use in making probabilistic projections. For example, its climate sensitivity can be varied by changing its cloud feedback and the rate of penetration of heat into the deep ocean can be varied by changing an appropriate mixing coefficient (Sokolov et al. 2005). This flexibility allows us to avoid, to a considerable extent, the structural rigidity that limits the ability of individual coupled AOGCMs to assess uncertainty in projections of global change. Also, the use of parameters' distributions as constrained by twentiethcentury temperature changes allows us to cover full uncertainty ranges for the climate system properties controlled by the model parameters. The economic and emissions component of the IGSM is driven by growth in the general economy and includes representation of final consumption and trade in all goods and services, including a relatively detailed treatment of factors driving emissions from energy, agriculture, waste, and industrial sources as they depend on resource availabilities and technological alternatives (Paltsev et al. 2005). The IGSM was used as part of the recent U.S. Climate Change Science Program (CCSP) scenarios exercise to generate a set of new global scenarios of emissions with and without policy intervention (Clarke et al. 2007) and so this work extends the scenario approach applied there to a probabilistic analysis.

Since Webster et al. (2003) was published, the IGSM has been upgraded as described by Sokolov et al. (2005). These upgrades include an increase in resolution of the atmospheric model, replacement of a zonally averaged mixed layer ocean model by a latitude-longitude resolving one, implementation of a more sophisticated land system model, and a more detailed representation of the national and regional economies of the world. In 
addition to the improvements made to the IGSM itself, the results presented here are based on a new analysis of factors contributing to uncertainty in emissions (Webster et al. 2008). Simulations of twentieth-century climate used to derive distributions of earth system properties (Forest et al. 2008) were carried out with a more complete set of natural and anthropogenic forcings than simulations used by Forest et al. (2002).

These changes led to relatively moderate changes in the distributions of both the projected emissions and the climate system's response to a given forcing. However, because of nonlinear interactions between these factors, the net effect has been to shift the distributions of warming and sea level rise substantially upward when compared to Webster et al. (2003). As discussed in detail in later sections, the overall shift in the distribution, which doubles the previous median estimate of warming, has no single major contributing factor but rather results from the combination of several changes.

One critical factor to consider is the source of the input distributions and the sensitivity of any results to them. In particular, the distributions presented by Forest et al. (2008) were obtained using estimates of changes in deep-ocean heat content for the 0-3000-m layer provided by Levitus et al. (2005). A recent update of the Levitus et al. (2005) analysis [given on the National Oceanic and Atmospheric Administration (NOAA) Web site] corrects for errors in the XBT data pointed out by Gouretski and Koltermann (2007) but nevertheless obtains virtually the same result as the original analysis. However, Gouretski and Koltermann (2007) and Domingues et al. (2008), who also attempt to take these errors into account, come up with different estimates of changes in the ocean heat content for the 0-3000-m layer. Sokolov et al. (2009) have shown that projections of future climate change are sensitive to the distributions of climate model parameters derived using these alternative estimates of the changes in deep-ocean heat content. For consistency with our earlier study (Webster et al. 2003), we carried out our simulations using the climate parameter distributions based on the analysis of Levitus et al. (2005). However, given the significant influence of the estimate of the ocean heat uptake on the projections, we also discuss the sensitivity of our results to other estimates of the changes in the heat content of the deep ocean.

Our results are also conditional on some other assumptions made in our study. For example, Forest et al. (2006) showed that posterior distributions of climate parameters are sensitive to the prior used for climate sensitivity. We, however, do not discuss in this paper the corresponding sensitivity of our climate projections. It also needs to be noted that, because of the lack of the necessary observations, we had to rely on AOGCM results for estimating long-term variability of different climate variables or for estimating possible changes in precipitation trends.

The outline of the paper is as follows: In section 2 the updated IGSM is described. Then in section 3 we present our methodology, enumerating the uncertainties taken into account, how they are characterized, and how the probabilistic projections are made. In section 4 we give our twenty-first-century projections for a variety of indicators of changes in the earth system including greenhouse gas (GHG) concentrations, surface air temperature (SAT) changes, and sea level rise (SLR) and we compare our results with those of Webster et al. (2003) and the IPCC's Fourth Assessment Report (AR4). Finally we give our conclusions in section 5 .

\section{Model components}

The MIT Integrated Global System Model includes submodels of the relevant parts of the natural earth system and a model of human activity. A description of the IGSM Version 1, along with sensitivity tests of key aspects of its behavior, was reported in Prinn et al. (1999). Version 2 of the IGSM (IGSM2; Sokolov et al. 2005) includes the following components (Fig. 1):

a model of human activities and emissions (the Emissions Prediction and Policy Analysis Model);

an atmospheric dynamics, physics, and chemistry model, which includes a submodel of urban chemistry;

a mixed layer-anomaly-diffusing ocean model (ADOM) with carbon cycle and sea ice submodels;

a land system model that combines the Terrestrial Ecosystem Model (TEM), a natural emissions model (NEM), and the Community Land Model (CLM), that together describe the global, terrestrial water, and energy budgets and terrestrial ecosystem processes.

The earth climate system component of the IGSM is a fully coupled model that allows simulation of critical feedbacks between components. The time steps used in the various submodels range from $10 \mathrm{~min}$ for atmospheric dynamics to 1 month for TEM, reflecting differences in the characteristic time scales of the various processes simulated by the IGSM.

The IGSM is distinguished from other similar models by its inclusion of significant chemical and biological detail. Our models of the terrestrial carbon, methane, and nitrous oxide cycles are coupled to climate, terrestrial hydrology, and land ecosystems models, which provide the needed explicit predictions of temperature, rainfall, and soil organic carbon concentrations. The 


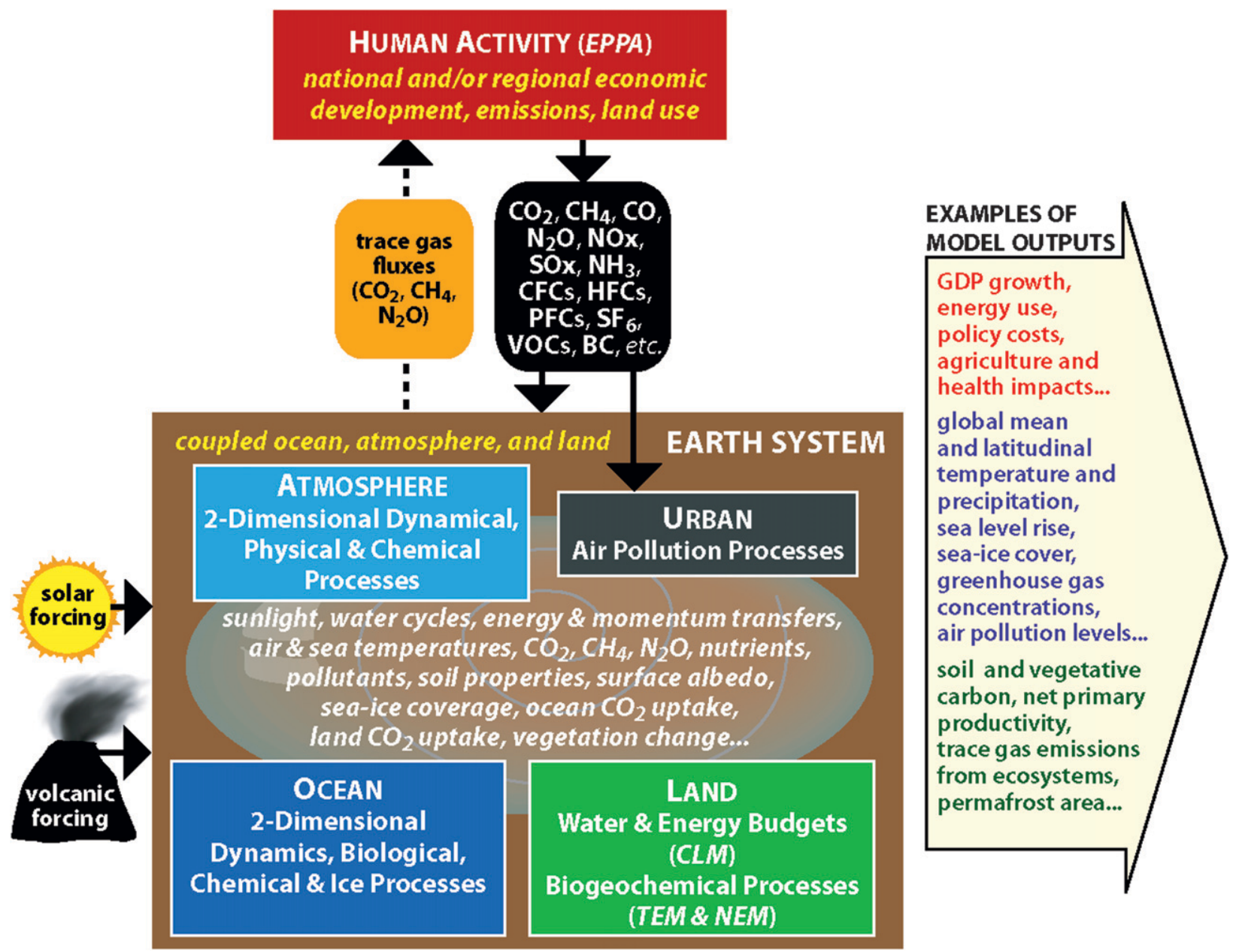

FIG. 1. The MIT IGSM Version 2.2.

prediction of global anthropogenic emissions of $\mathrm{CO}_{2}$, $\mathrm{CO}, \mathrm{NO}_{\mathrm{x}}$, black carbon, $\mathrm{SO}_{\mathrm{x}}$, and other key species is based on a regionally disaggregated model of global economic growth. This procedure allows for treatment over time of a shifting geographical distribution of emissions, changing mixes of these emissions, and recognition of the fact that the emissions of chemicals important in air pollution and climate are highly correlated because of shared generating processes like combustion.

The major model components of the IGSM2 and recent developments in their capabilities and linkages are summarized below.

\section{a. Human activity and emissions}

The EPPA model is a general equilibrium model of the world economy developed by the MIT Joint Program on the Science and Policy of Global Change (Paltsev et al. 2005). For economic data, it relies on the Global Trade, Assistance, and Production (GTAP) dataset (Dimaranan and McDougall 2002), which accommodates a consistent representation of regional macroeconomic consumption, production, and bilateral trade flows. The energy data in physical units are based on energy balances from the International Energy Agency. The EPPA model also uses additional data for past greenhouse gas emissions [carbon dioxide $\left(\mathrm{CO}_{2}\right)$, methane $\left(\mathrm{CH}_{4}\right)$, nitrous oxide $\left(\mathrm{N}_{2} \mathrm{O}\right)$, hydrofluorocarbons (HFCs), perfluorocarbons (PFCs), and sulfur hexafluoride $\left.\left(\mathrm{SF}_{6}\right)\right]$ and past air pollutant emissions [sulfur dioxide $\left(\mathrm{SO}_{2}\right)$, nitrogen oxides $\left(\mathrm{NO}_{\mathrm{x}}\right)$, black carbon (BC), organic carbon (OC), ammonia $\left(\mathrm{NH}_{3}\right)$, carbon monoxide $(\mathrm{CO})$, and nonmethane volatile organic compounds (VOC)] based on U.S. Environmental Protection Agency inventory data supplemented by our own estimates.

Much of the model's sectoral detail is focused on energy production to represent technological alternatives in electric generation and transportation. From 2000 to 2100 the model is solved recursively at 5 -yr intervals. The EPPA model has been used in a wide variety of policy applications (e.g., Jacoby et al. 1997; Reilly et al. 
1999; Babiker et al. 2003; Reilly and Paltsev 2006; Clarke et al. 2007; Paltsev et al. 2008) and in economic model intercomparison projects (e.g., Weyant and Hill 1999; Weyant 2004; Weyant et al. 2006).

Because climate and energy policy are our main focus, the model further disaggregates the data for transportation and existing energy supply technologies and includes a number of alternative sources that are not in widespread use now but could take market share in the future under changed energy prices or climate policy conditions. Bottom-up engineering details are incorporated in the EPPA model in the representation of these alternative energy supply technologies. The competitiveness of different technologies depends on the endogenously determined prices for all inputs, and those prices depend in turn on depletion of resources, economic policy, and other forces driving economic growth such as savings, investment, energy efficiency improvements, and productivity of labor. Additional information on the model's structure can be found in Paltsev et al. (2005).

\section{b. Atmospheric dynamics and physics}

The MIT two-dimensional (2D) atmospheric dynamics and physics model (Sokolov and Stone 1998) is a zonally averaged statistical-dynamical model that explicitly solves the primitive equations for the zonal mean state of the atmosphere and includes parameterizations of heat, moisture, and momentum transports by large-scale eddies based on baroclinic wave theory (Stone and Yao 1987, 1990). The model's numerics and parameterizations of physical processes, including clouds, convection, precipitation, radiation, boundary layer processes, and surface fluxes, are built upon those of the Goddard Institute for Space Studies (GISS) GCM (Hansen et al. 1983). The radiation code includes all significant greenhouse gases $\left(\mathrm{H}_{2} \mathrm{O}, \mathrm{CO}_{2}, \mathrm{CH}_{4}, \mathrm{~N}_{2} \mathrm{O}, \mathrm{CFCs}\right.$, and $\left.\mathrm{O}_{3}\right)$ and 11 types of aerosols. The model's horizontal and vertical resolutions are variable, but the standard version of IGSM2 has $4^{\circ}$ resolution in latitude and 11 levels in the vertical.

The MIT 2D atmospheric model allows up to four different types of underlying surface in each grid cell (ice-free ocean, sea ice, land, and land ice). The surface characteristics (e.g., temperature, soil moisture, albedo) as well as turbulent and radiative fluxes are calculated separately for surface type. The atmosphere above is assumed to be well mixed zonally in each latitudinal band. The area-weighted fluxes from the different surface types are used to calculate the change of temperature, humidity, and wind speed in the atmosphere. Convection and large-scale condensation are simulated under the assumptions that a zonal band may be partially unstable or partially saturated, respectively. The moist convection parameterization, which was originally designed for the GISS Model I (Hansen et al. 1983), requires knowledge of subgrid-scale temperature variance. Zonal temperature variance associated with transient eddies is calculated using a parameterization proposed by Branscome (see Yao and Stone 1987). The variance associated with stationary eddies was represented in the IGSM1 by adding a fixed variance of $2 \mathrm{~K}$ at all latitudes. In the IGSM2 we introduce a latitudinal dependence of the latter variance that follows more closely the climatological pattern (see Figure. $7.8 \mathrm{~b}$ of Peixoto and Oort 1992). In addition, the threshold values of relative humidity for the formation of large-scale cloud and precipitation have been modified such that a constant value for all latitudes (as used in the IGSM1) is replaced with latitudinally varying values. This modification is made to account for the dependence of the zonal variability of relative humidity on latitude. Zonal precipitations simulated by the atmospheric model are partitioned into land and ocean components using present-day climatology. These changes led to an improvement in the zonal pattern of the annual cycle of land precipitation and evapotranspiration (Schlosser et al. 2007).

The atmospheric model's climate sensitivity can be changed by varying the cloud feedback. The method for changing this feedback in the model has been changed from the method used previously. In the IGSM1 the cloud cover at all levels was changed by a fixed fraction, which depended on the global mean surface temperature (Sokolov and Stone 1998). In the IGSM2 high cloud covers and low cloud covers are changed in opposite directions by a constant factor, which is again dependent on the global mean surface temperature. The new method, described by Sokolov (2006), shows better agreement with changes simulated by AOGCMs.

\section{c. Atmospheric chemistry}

To calculate atmospheric composition, the model of atmospheric chemistry includes an analysis of the climaterelevant reactive gases and aerosols at urban scales coupled to a model of the processing of exported pollutants from urban areas (plus the emissions from nonurban areas) at the regional to global scale. For calculation of the atmospheric composition in nonurban areas, the above atmospheric dynamics and physics model is linked to a detailed 2D zonal mean model of atmospheric chemistry. The atmospheric chemical reactions are thus simulated in two separate modules: one for the 2D model grids and one for the subgrid-scale urban chemistry.

\section{1) URBAN AIR CHEMISTRY}

The analysis of the atmospheric chemistry of key substances as they are emitted into polluted urban areas is an important addition to the integrated system since 
the version described in Prinn et al. (1999). Urban air pollution is explicitly treated in the IGSM for several reasons. It has a significant impact on global methane, ozone, and aerosol chemistry, and thus on climate. However, the nonlinearities in the chemistry cause urban emissions to undergo different net transformations than rural emissions. Accuracy in describing these transformations is necessary because the atmospheric life cycles of exported air pollutants such as $\mathrm{CO}, \mathrm{O}_{3}, \mathrm{NO}_{\mathrm{x}}$, and VOCs, and the climatically important species $\mathrm{CH}_{4}$ and sulfate aerosols, are linked through the fast photochemistry of the hydroxyl free radical $(\mathrm{OH})$, as we will emphasize in the results discussed later in section 4 . Urban airshed conditions need to be resolved at varying levels of pollution. The urban air chemistry model must also provide detailed information about particulates and their precursors important to air chemistry and human health and about the effects of local topography and structure of urban development on the level of containment and thus the intensity of air pollution events. This is an important consideration because air pollutant levels are dependent on projected emissions per unit area, not just total urban emissions.

The urban atmospheric chemistry model has been introduced as an additional component to the original global model (Prinn et al. 1999) in IGSM1 (Calbo et al. 1998; Mayer et al. 2000; Prinn et al. 2007). It was derived by fitting multiple runs of the detailed 3D California Institute of Technology (CIT) Urban Airshed Model, adopting the probabilistic collocation method to express outputs from the CIT model in terms of model inputs using polynomial chaos expansions (Tatang et al. 1997). This procedure results in a reduced format model to represent about 200 gaseous and aqueous pollutants and associated reactions over urban areas that is computationally efficient enough to be embedded in the global model. The urban module is formulated to take meteorological parameters including wind speed, temperature, cloud cover, and precipitation as well as urban emissions as inputs. Calculated with a daily time step, it exports fluxes along with concentrations (peak and mean) of selected pollutants to the global model.

\section{2) Global ATMOsPheric CHEMistry}

The 2D zonal mean model that is used to calculate atmospheric composition is a finite-difference model in latitude-pressure coordinates, and the continuity equations for trace constituents are solved in mass conservative or flux form (Wang et al. 1998). The model includes 33 chemical species. The continuity equations for $\mathrm{CFCl}_{3}, \mathrm{CF}_{2} \mathrm{Cl}_{2}, \mathrm{~N}_{2} \mathrm{O}, \mathrm{O}_{3}, \mathrm{CO}, \mathrm{CO}_{2}, \mathrm{NO}, \mathrm{NO}_{2}, \mathrm{~N}_{2} \mathrm{O}_{5}$, $\mathrm{HNO}_{3}, \mathrm{CH}_{4}, \mathrm{CH}_{2} \mathrm{O}, \mathrm{SO}_{2}, \mathrm{H}_{2} \mathrm{SO}_{4}, \mathrm{HFC}, \mathrm{PFC}, \mathrm{SF}_{6}$, black carbon aerosol, and organic carbon aerosol include convergences due to transport, parameterized northsouth eddy transport, convective transports, local true production or loss due to surface emission or deposition, and atmospheric chemical reactions. In contrast to these gases and aerosols, the very reactive atoms (e.g., O), free radicals (e.g., $\mathrm{OH}$ ), or molecules (e.g., $\mathrm{H}_{2} \mathrm{O}_{2}$ ) are assumed to be unaffected by transport because of their very short lifetimes; only chemical production and/or loss (in the gaseous or aqueous phase) is considered in the predictions of their atmospheric abundances.

There are 41 gas-phase and 12 heterogeneous reactions in the background chemistry module applied to the 2D model grid. The scavenging of carbonaceous and sulfate aerosol species by precipitation is also included using a method based on a detailed 3D climate-aerosolchemistry model (Wang 2004). Water vapor and air $\left(\mathrm{N}_{2}\right.$ and $\mathrm{O}_{2}$ ) mass densities are computed using full continuity equations as a part of the atmospheric dynamics and physics model to which the chemical model is coupled. The climate model also provides wind speeds, temperatures, solar radiation fluxes, and precipitation, which are used in both the global and urban chemistry formulations.

\section{3) COUPLing OF GLOBAL AND URBAN CHEMISTRY MODULES}

The urban chemistry module was derived based on an ensemble of 24-h-long CIT model runs and thus is processed in the IGSM with a daily time step, while the global chemistry module is run in a real time step with the dynamics and physics model: 20 min for advection and scavenging and $3 \mathrm{~h}$ for tropospheric reactions. The two modules in the IGSM are processed separately at the beginning of each model day, supplied by emissions of nonurban and urban regions, respectively. At the end of each model day, the predicted concentrations of chemical species by the urban and global chemistry modules are then remapped based on the urban-tononurban volume ratio at each model grid. Beyond this step, the resultant concentrations at each model grid will be used as the background concentration for the next urban module prediction and also as initial values for the global chemistry module (Mayer et al. 2000).

\section{d. Ocean component}

In the older IGSM1 (Prinn et al. 1999) a zonally averaged mixed layer ocean model with $7.8^{\circ}$ latitudinal resolution was used. In the new IGSM2 the ocean component has been replaced by either a two-dimensional (latitude-longitude) mixed layer anomaly-diffusing ocean model (hereafter denoted as IGSM2.2) or a fully threedimensional ocean GCM (denoted as IGSM2.3). Dalan et al. (2005b) showed that different versions of the 3D 
ocean model with different rates of heat uptake can be produced by changing the vertical-diapycnal diffusion coefficients. However, changing the diapycnal coefficient also alters the ocean circulation, in particular the strength of North Atlantic overturning (Dalan et al. 2005a). Unfortunately, it appears infeasible (certainly without changes to parameterizations in the $3 \mathrm{D}$ models) to vary the heat uptake over the full range consistent with observations during the twentieth century (Forest et al. 2008) and at the same time maintain a reasonable circulation.

The ocean component of the IGSM2.2 consists of a Q-flux mixed layer model with horizontal resolution of $4^{\circ}$ in latitude and $5^{\circ}$ in longitude, and a 3000-m-deep anomaly-diffusing ocean model beneath. The mixed layer depth is prescribed based on observations as a function of time and location (Hansen et al. 1983). In addition to the temperature of the mixed layer, the model also calculates the averaged temperature of the seasonal thermocline and the temperature at the annual maximum mixed layer depth (Russell et al. 1985). Diffusion in the deep-ocean model is applied to the difference in the temperature at the bottom of the seasonal thermocline relative to its value in a present-day climate simulation (Hansen et al. 1984; Sokolov and Stone 1998). Since this diffusion represents a cumulative effect of heat mixing by all physical processes, the values of the diffusion coefficients are significantly larger than those used in subgrid-scale diffusion parameterizations in OGCMs. The spatial distribution of the diffusion coefficients used in the diffusive model is based on observations of tritium mixing into the deep ocean (Hansen et al. 1988). For simulations with different rates of oceanic heat uptake, the coefficients are scaled by the same factor in all locations.

The coupling between the atmospheric and oceanic components takes place every hour and is described by Kamenkovich et al. (2002) and Sokolov et al. (2005).

The mixed layer model also includes a specified vertically integrated horizontal heat transport by the deep oceans, a so-called "Q flux," allowing zonal as well as meridional transport. This flux is calculated from a simulation in which sea surface temperature (SST) and sea ice distribution are relaxed toward their present-day climatology with relaxation coefficient of $300 \mathrm{~W} \mathrm{~m}^{-2} \mathrm{~K}^{-1}$, which corresponds to an $e$-folding time scale of about 15 days for a 100-m-deep mixed layer. Relaxing SST and sea ice on such a short time scale, while being virtually identical to specifying them, avoids problems with calculating the $\mathrm{Q}$ flux near the sea ice edge. The use of a two-dimensional (longitude-latitude) mixed layer ocean model instead of the zonally averaged one used in IGSM1 has allowed a better simulation of both the present-day sea ice distribution and sea ice changes in response to increasing radiative forcing (Sokolov et al. 2005).
A thermodynamic ice model is used for representing sea ice. This model has two ice layers and computes ice concentration (the percentage of area covered by ice) and ice thickness.

The IGSM2.2 includes a significantly modified version of the ocean carbon model (Holian et al. 2001) used in the IGSM1. Formulation of carbonate chemistry (Follows et al. 2006) and parameterization of air-sea fluxes in this model are similar to the ones used in the IGSM2.3. Vertical and horizontal transports of the total dissolved inorganic carbon, though, are still parameterized by diffusive processes. The values of the horizontal diffusion coefficients are taken from Stocker et al. (1994), and the coefficient of vertical diffusion of carbon $\left(K_{v c}\right)$ depends on the coefficient of vertical diffusion of heat anomalies $\left(K_{v}\right)$. In IGSM1, $K_{v c}$ was assumed to be proportional to $K_{v}$ (Prinn et al. 1999; Sokolov et al. 1998). This assumption, however, does not take into account the vertical transport of carbon due to the biological pump. In the IGSM2.2 $K_{v c}$ is, therefore, defined as

$$
K_{v c}=K_{v c o}+r K_{v} .
$$

Since $K_{v c o}$ is a constant, the vertical diffusion coefficients for carbon have the same latitudinal distribution as the coefficients for heat. For simulations with different rates of oceanic uptake, the diffusion coefficients are scaled by the same factor in all locations. Therefore rates of both heat and carbon uptake by the ocean are defined by the global mean value of the diffusion coefficient for heat. In the rest of the paper the symbol $K_{v}$ is used to designate the global mean value.

Comparisons with 3D ocean simulations have shown that the assumption that changes in ocean carbon can be simulated by the diffusive model with fixed diffusion coefficient, as used in the IGSM1, works only for about 150 yr. On longer time scales the simplified carbon model overestimates the ocean carbon uptake. However, if $K_{v c}$ is assumed to be time dependent, the IGSM2.2 reproduces changes in ocean carbon as simulated by the IGSM2.3 on multicentury scales (Sokolov et al. 2007). Thus, for the runs discussed here, the coefficient for vertical diffusion of carbon was calculated as

$$
K_{v c}(t)=\left(K_{v c o}+r K_{v}\right) f(t)
$$

where $f(t)$ is a time-dependent function constructed based on the analyses of the depths of carbon mixing in simulations with the IGSM2.3.

To evaluate the performance of the ADOM on different time scales, Sokolov et al. (2007) carried out a detailed comparison of the results of simulations with the two versions of the IGSM2. Our results show that, in 
spite of its inability to depict feedbacks associated with the changes in the ocean circulation and a very simple parameterization of the ocean carbon cycle, the version of the IGSM2 with the ADOM is able to reproduce the important aspects of the climate response simulated by the version with the OCGM through the twentieth and twenty-first century and can be used to produce probabilistic projections of changes in many of the important climate variables, such as surface air temperature and sea level, through the end of the twenty-first century.

\section{e. Global Land System}

The Global Land System framework (GLS; Schlosser et al. 2007) integrates three existing models: the CLM (e.g., Bonan et al. 2002), the TEM (e.g., Melillo et al. 1993; Felzer et al. 2004), and an NEM (Liu 1996). The GLS uses the CLM representation of the coupling of the biogeophysical characteristics and fluxes between the atmosphere and land (e.g., evapotranspiration, surface temperatures, albedo, surface roughness, and snow depth). In addition, the CLM provides all of the hydrothermal states and fluxes (e.g., soil moisture, soil temperatures, evaporation, and precipitation events) at the appropriate spatial and temporal scales required by TEM and NEM. The TEM is then used to estimate changes in terrestrial carbon storage and the net flux of carbon dioxide between land and the atmosphere as a result of ecosystem metabolism. The NEM estimates the net flux of methane from global wetlands and tundra ecosystems and the net flux of nitrous oxide from all natural terrestrial ecosystems to the atmosphere. The submodule in NEM describing processes leading to nitrous oxide emissions is primarily a globalization of the Denitrification Decomposition (DNDC) model of $\mathrm{Li}$ et al. (1992). Within the GLS, the algorithms of NEM that describe methane $\left(\mathrm{CH}_{4}\right)$ and nitrous oxide $\left(\mathrm{N}_{2} \mathrm{O}\right)$ dynamics have been incorporated into TEM so that TEM now describes the hourly and daily dynamics of these trace gases in addition to the monthly dynamics of carbon dioxide and organic matter in terrestrial ecosystems. The direct coupling between these two models allows monthly TEM estimates of reactive soil organic carbon to determine nitrous oxide fluxes. In addition, a new procedure has been developed that provides a statistical representation of the episodic nature and spatial distribution of land precipitation. This is required for two reasons: 1) an "episodic" provision of zonal precipitation from the IGSM's atmospheric submodel represents more realistic hydrologic forcing to CLM than a constant precipitation rate applied at every time step for every zonal band, and 2) the $\mathrm{N}_{2} \mathrm{O}$ module of NEM requires precipitation events that vary in intensity and duration along with corresponding dry periods between storm events to employ its decomposition, nitrification, and denitrification parameterizations.

All land areas across the globe are assumed by TEM and NEM to be covered by natural vegetation, which is held constant in time. To match and couple with the zonal configuration of the atmospheric dynamics and chemistry, the areas for each land cover type at the native $0.5^{\circ}$ latitude $\times 0.5^{\circ}$ longitude grid cells (employed by both CLM and TEM) have been aggregated within each $4^{\circ}$ latitudinal band used by the atmospheric dynamics and chemistry model (Schlosser et al. 2007). Thus, each latitudinal band represents a $4^{\circ}$ latitude $\times 360^{\circ}$ longitude grid cell in the GLS framework. The GLS is run for all land cover types found in these zonal cells, and the area covered by each land cover type is used to determine the relative contribution of that land cover type to the zonally aggregated water, energy, carbon, and nitrogen fluxes from the terrestrial systems. As shown by Schlosser et al. (2007), the zonal fluxes from GLS are not substantially affected by the implementation the of zonal mosaic land cover data in the IGSM2 as compared to their performance using explicit latitude-longitude grids. The timing and location of the carbon sink and source regions is preserved, and the spatiotemporal patterns of evapotranspiration agree well with a consensus of state-of-theart biogeophysical models as determined by the Global Soil Wetness Project Phase 2 (GSWP2; Dirmeyer et al. 2002). Moreover, one of the more desirable changes in the patterns of carbon flux by TEM in the zonal GLS configuration, as compared to a previous version of TEM employed in the IGSM, is the removal of an erroneous midsummer carbon emission at northern high latitudes, which is not seen in spatially explicit TEM simulations forced by observed atmospheric conditions (refer to Schlosser et al. 2007 for more details).

In TEM, the potential uptake of atmospheric $\mathrm{CO}_{2}$ by plants is assumed to follow Michaelis-Menten kinetics, according to which the effect of atmospheric $\mathrm{CO}_{2}$ at time $t$ on the assimilation of $\mathrm{CO}_{2}$ by plants is parameterized as follows:

$$
\left[\mathrm{CO}_{2}(t)\right]=\frac{\left[C_{\max } \mathrm{CO}_{2}(t)\right]}{\left[k c+\mathrm{CO}_{2}(t)\right]},
$$

where $C_{\max }$ is the maximum rate of $C$ assimilation, and $k c$ is the $\mathrm{CO}_{2}$ concentration at which $C$ assimilation proceeds at one-half of its maximum rate (i.e., $C_{\max }$ ). As shown by Sokolov et al. (2008), a change in $k c$ affects both the response of TEM to an increase in atmospheric $\mathrm{CO}_{2}$ concentration and the strength of the feedback between climate and the terrestrial carbon cycle.

In contrast to most of the terrestrial biosphere models currently used in climate change assessments (Plattner 
et al. 2008), TEM takes in to account nitrogen limitations on net carbon storage. This significantly decreases the sensitivity of the terrestrial carbon uptake to the increase in the atmospheric $\mathrm{CO}_{2}$ concentration and affects the sign of the feedback between the terrestrial carbon cycle and climate (Sokolov et al. 2008).

\section{Methodology}

\section{a. General approach for making projections}

The basic method we employ for uncertainty analysis is Monte Carlo simulation, in which multiple input sets are sampled from probability distributions representing uncertainty in input parameters. Pure random sampling typically requires many thousands of samples to converge to a stable distribution of the model output. Therefore, a number of alternative more efficient sampling strategies have been developed. In this study, we use Latin hypercube sampling (LHS) (Iman and Helton 1988). LHS divides each parameter distribution into $n$ segments of equal probability, where $n$ is the number of samples to be generated. Sampling without replacement is performed so that with $n$ samples every segment is used once. We use a sample size of 400 for each s simulation ensemble. The 400 runs adequately constrain the $5 \%$ and $95 \%$ bounds, as tested by a separate 1000-member ensemble.

\section{b. Physical and scientific uncertainties}

\section{1) Climate sensitivity, MiXing OF HeAt into THE OCEAN, AND AEROSOL FORCING}

Three properties that are commonly recognized as being major contributors to the uncertainty in simulations of future climate change are the effective climate sensitivity of the system $(S)$, the rate at which heat is mixed into the deep ocean $\left(K_{v}\right)$, and the strength of the aerosol forcing associated with a given aerosol loading $\left(F_{\text {aer }}\right)$ (Meehl et al. 2007a). These same properties and their uncertainties also affect twentieth-century simulations. Thus, in principle, estimates of these properties and their uncertainties can be derived from simulations in which these properties are varied to determine which give simulations consistent with observed twentieth-century changes.

In the present study, we use the probability density functions (pdfs) estimated in this way by Forest et al. (2008). The values of $S, K_{v}$, and $F_{\text {aer }}$ were varied systematically in the climate model component of the IGSM and a large ensemble $(\sim 600)$ of simulations of twentieth-century climate was carried out. The simulations were compared against observations of surface, upper-air, and deep-ocean temperature changes. For each diagnostic the likelihood that a given simulation is consistent with the observed changes, allowing for observational error and natural var- iability, was estimated using goodness-of-fit statistics from climate change detection methods (see Forest et al. 2002, 2006, 2008). By combining the likelihood distributions estimated from each diagnostic using Bayes' theorem, a posterior probability distribution was obtained. As with other estimates of probability distributions using Bayesian methods, priors on the three parameters are required. For climate sensitivity, the prior distribution was calculated by Webster and Sokolov (2000) from an expert elicitation by Morgan and Keith (1995). This prior essentially limits the possible climate sensitivities to being less than $7^{\circ} \mathrm{C}$, consistent with expert opinion (Webster and Sokolov 2000; Hegerl et al. 2007). Uniform distributions were used as priors for the other two parameters.

The sensitivity of the posterior distributions to the use of the expert prior for climate sensitivity was discussed by Forest et al. (2006). We, however, have not studied the corresponding sensitivity of our projections of future climate.

The resulting two-dimensional marginal distribution for effective climate sensitivity and the rate of deepocean heat uptake is shown in Fig. 2, along with the locations in this parameter space of $10 \mathrm{AOGCMs}^{1}$ [estimated from data in the phase 3 of the Coupled Model Intercomparison Project (CMIP3) archive; Meehl et al. 2007b]. The joint distribution differs significantly from the earlier distribution, developed in Forest et al. (2002) and used in Webster et al. (2003), because the model simulations for the twentieth century used by Forest et al. $(2006,2008)$ include several additional forcings. Most importantly they include stratospheric aerosols from volcanic eruptions and, because these caused a cooling in the latter half of the twentieth century, higher climate sensitivities and lower rates of ocean heat uptake are required to match the observed temperature changes. The effect of these shifts in the probability distribution can be summarized in the likelihood distribution for changes in surface air temperature and thermosteric sea level rise due to $\mathrm{CO}_{2}$ increase at $1 \% \mathrm{yr}^{-1}$ rate (Fig. 3). The higher lower bound for transient climate response (TCR) and lower upper bound for sea level rise are a direct result of the shift in the distributions for climate sensitivity and the effective thermal diffusivity.

The LHS sampling method used in Webster et al. (2003) generated samples for $K_{v}, S$, and Faer from their

\footnotetext{
${ }^{1}$ Positions of the AOGCMs relative to ranges of climate parameters suggested by observation strongly depend on data on changes in deep-ocean heat content. As shown by Sokolov et al. (2009), models fall in the upper half of the diffusion coefficient range suggested by Levitus et al. (2005) estimates. At the same time they all fall in the lower half of the range suggested by the Domingues et al. (2008) data.
} 


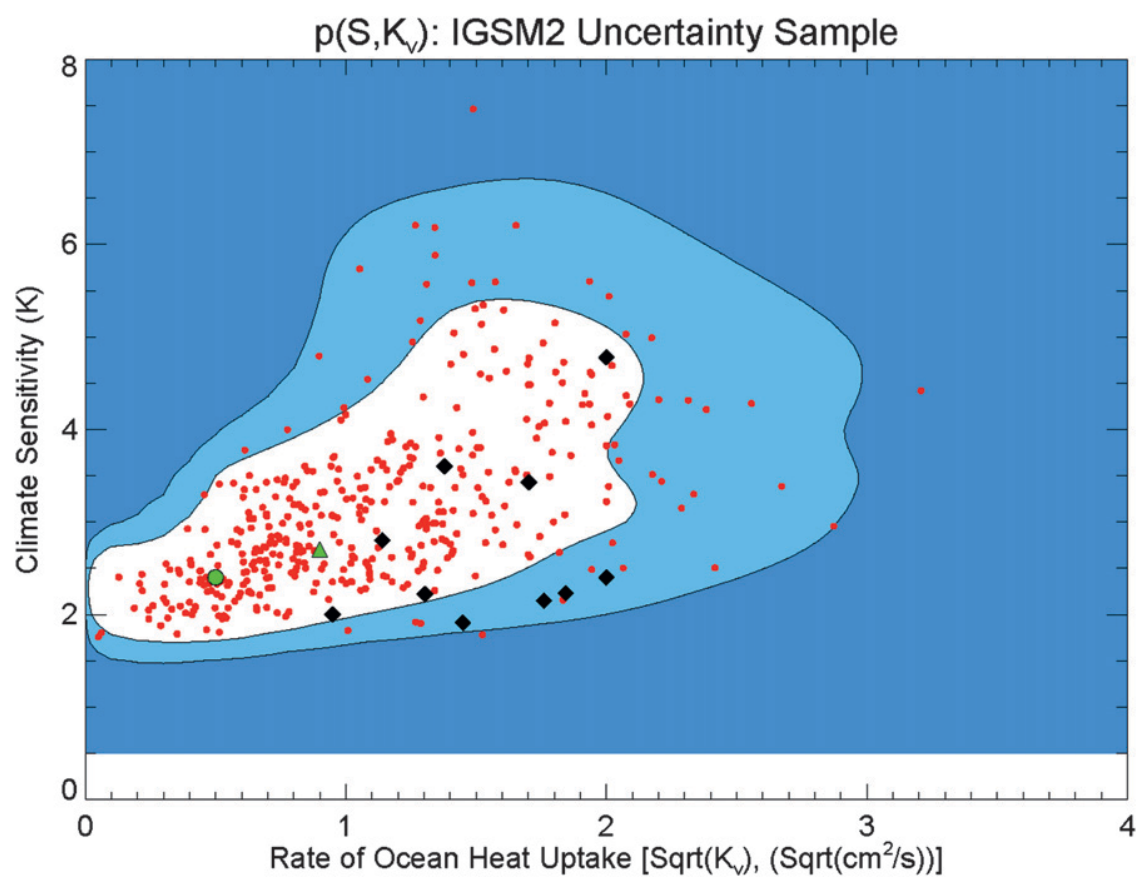

FIG. 2. The marginal posterior probability density function for $S-K_{v}$ parameter space. The shading and thick contours denote rejection regions for significance levels of $10 \%$ and $1 \%$, respectively. Green circle and triangle indicate mode and a median on the distribution, respectively. Black diamonds indicate values of the parameters of the MIT climate model needed to represent behavior of different AR4 AOGCMs in the simulations with $1 \% \mathrm{yr}^{-1}$ increases in the $\mathrm{CO}_{2}$ concentration. Red dots show values for $K_{v}$ and $S$ from 400 samples.

individual 1D marginal pdfs and imposed the correlation structure of the joint 3D pdf on the samples. In contrast, now after picking a $K_{v}$ sample from the 1D marginal pdf, we generate a $2 \mathrm{D}$ pdf for $S$ and $F_{\text {aer }}$ conditional on the chosen $K_{v}$ value, calculate a $1 \mathrm{D}$ marginal pdf for $S$ from that 2D pdf, and sample the new pdf for $S$. Finally, we generate a $1 \mathrm{D}$ pdf for $F_{\text {aer }}$ conditional on the two chosen values of $K_{v}$ and $S$ and sample that pdf for a value of $F_{\text {aer }}$. This new sampling strategy preserves the uniqueness of the samples by not allowing one to choose from the same bin number in the conditional pdfs, though it theoretically may sample the same value of $S$ or $F_{\text {aer }}$ fewer times in contrast to the earlier method. The new method better preserves the full details of the original three-dimensional pdf. Values for $K_{v}$ and $S$ from the 400 samples are shown on Fig. 2 by red dots.

\section{2) UNCERTAINTY IN CARBON CYCLE}

As described in section $2 \mathrm{~d}$, the vertical diffusion coefficient for carbon depends on the effective vertical diffusivity for temperature anomalies; thereby, uncertainty in carbon uptake by the ocean is linked to the uncertainty in heat uptake. Values of the parameters in the equation for $K_{v c}$ [Eq. (1)] were estimated so that, for the range of $K_{v}$, deduced from observations, the oceanic carbon uptake for the 1980s spans the observed uncertainty range given in the IPCC Third Assessment Report (TAR). The values of $K_{v c o}$ and $r$ that satisfy this requirement are $1.0 \mathrm{~cm}^{2} \mathrm{~s}^{-1}$ and 3.0, respectively.

In contrast to Webster et al. (2003), in the present study we take into account uncertainty in the fertilization effect of atmospheric $\mathrm{CO}_{2}$. The results of $\mathrm{CO}_{2}-$ enrichment studies suggest that plant growth could increase from $24 \%$ to $50 \%$ in response to doubled $\mathrm{CO}_{2}$ given adequate nutrients and water (Raich et al. 1991; McGuire et al. 1992; Gunderson and Wullschleger 1994; Curtis and Wang 1998; Norby et al. 2005). In TEM, a value of $400 \mathrm{ppmv} \mathrm{CO}_{2}$ is normally chosen for the halfsaturation constant $k c$ [Eq. (3)] so that $f\left[\mathrm{CO}_{2}(t)\right]$ increases by $37 \%$ for a doubling of atmospheric $\mathrm{CO}_{2}$ from 340 to 680 ppmv $\mathrm{CO}_{2}$ (McGuire et al. 1992, 1993, 1997; Pan et al. 1998). A $24 \%$ response to doubled $\mathrm{CO}_{2}$ would

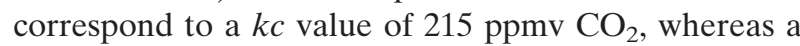
$50 \%$ ppmv $\mathrm{CO}_{2}$ response would correspond to a $k c$ value of $680 \mathrm{ppmv} \mathrm{CO}_{2}$ for the same changes in atmospheric $\mathrm{CO}_{2}$. As these enrichment studies may not have covered the full range of uncertainty, we used a uniform distribution of $k c$ with 150 ppmv as a low bound and 700 ppmv as the upper limit. 

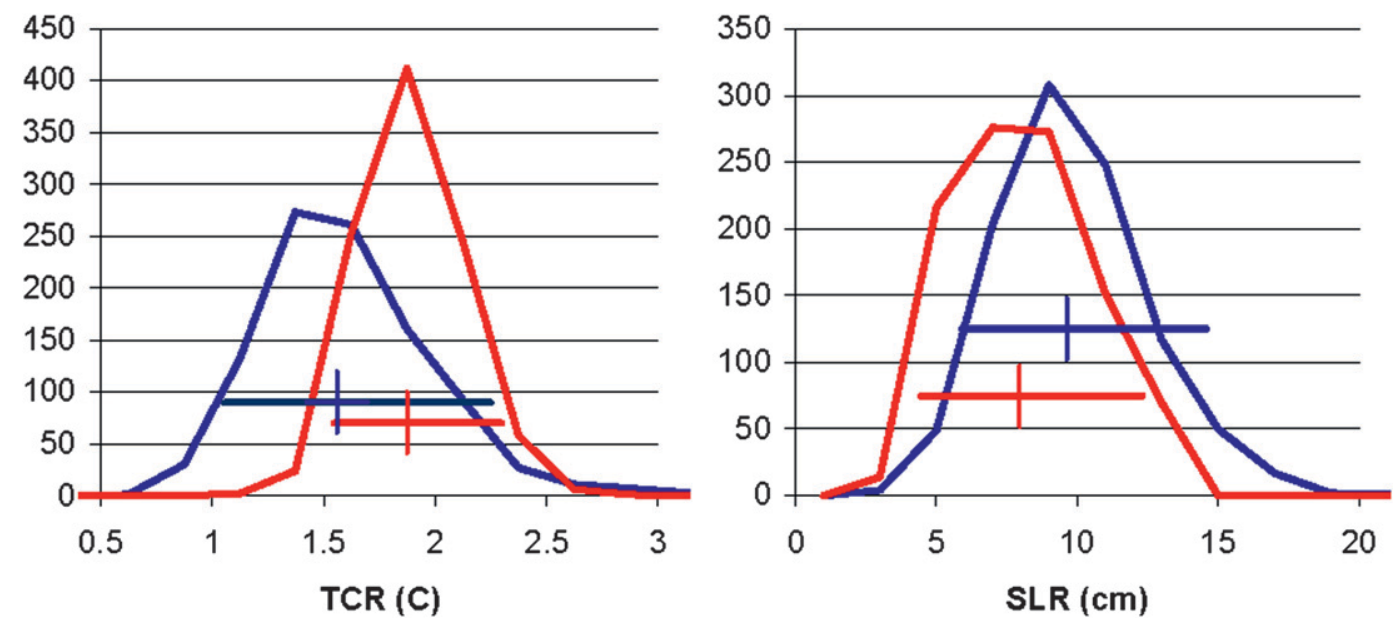

FIG. 3. Frequency distributions for changes in surface air temperature and thermosteric sea level rise averaged over years 61-80 in simulations with $1 \% \mathrm{yr}^{-1} \mathrm{CO}_{2}$ increase, obtained from the fits for the IGSM1 (blue) and IGSM2.2 (red) using climate parameter distributions from Forest et al. (2002) and Forest et al. (2008), respectively.

\section{3) Precipitation FReQuency}

Another physical uncertainty in the coupled earth system model is how the frequency of precipitation changes with increases in surface temperature. Changes in mean precipitation (over space and time) are fundamentally a result of shifts in the character of individual precipitation events, which are determined by the frequency at which they occur as well as their duration and intensity. It is these quantities that, in large part, determine the hydrologic climate of any region (i.e., the partitioning of precipitation between evaporation and runoff) as well as the ecology and biogeochemistry of the ecosystems. For example, more runoff results in greater flood potential, less water infiltration into the soils, and less storage available to plants as well as fewer saturating events that can impede nitrous oxide emissions (from soils) as well as methane-emitting environments. Such responses to climate change can have substantial consequences on natural and managed terrestrial systems and can provide potentially strong feedback mechanisms to the rest of the climate system. We therefore introduce an approach that provides a probability-based extrapolation of precipitation frequency change associated with climate warming.

Lacking observations adequate for estimating this trend, we use the results of the AOGCMs that participated in the IPCC AR4 to develop probability distributions of the trend. From the model archive, we consider the preindustrial control runs and the transient $\mathrm{CO}_{2}$ doubling runs in which the daily outputs of precipitation are archived for at least a 20 -yr period. For every grid point of the GCMs' time series, we determine for each day whether the model produced a sufficient amount of precipitation to be construed as a "wet" day. In doing so, our calculations require a threshold value for the daily precipitation rate of a grid cell above which we deem a precipitation "event" has occurred for that day. For this threshold we have chosen $2.5 \mathrm{~mm}^{\text {day }}{ }^{-1}$. From this, we determine for each month of the simulation period the total number of days that a precipitation event occurred and subsequently the average number of days between wet days for the month. To obtain a representative monthly climatology of these precipitation intervals, we calculate these statistics for each month, for every grid cell, and average them over the 20-yr period for the preindustrial runs as well as the transient run; the latter centered at the time of doubling of $\mathrm{CO}_{2}$. Then, by taking the difference in these monthly constructions of precipitation interval, we can infer any particular GCM's propensity to change under forced climate change (i.e., to a doubling of $\mathrm{CO}_{2}$ concentrations). Then, to configure these results to the IGSM zonal atmospheric structure, these gridded results are averaged over each of the GCMs' latitude bands. Once obtained, these (simulated) changes in this derived hydrologic diagnostic are associated with each AOGCM's change in global temperature. Thus, the zonally averaged changes in precipitation interval from each AOGCM are normalized according to their global temperature change.

Detailed analysis of the precipitation trends from the GCM data showed significant correlation within ranges of latitude. Based on the data, we group the $4^{\circ}$ zonal bands in the IGSM into the following aggregated zones: $54^{\circ}-28^{\circ} \mathrm{S}, 28^{\circ} \mathrm{S}-0^{\circ}, 0^{\circ}-24^{\circ} \mathrm{N}, 24^{\circ}-40^{\circ} \mathrm{N}$, and $40^{\circ}-84^{\circ} \mathrm{N}$. Once we have calculated these pooled, zonally averaged 
normalized changes in precipitation interval, based on the AR4 AOGCMs, we fit probability density functions to the distributions from the models.

Correlation between the $4^{\circ}$ zonal bands within each aggregated zone is accounted for as a part of the LHS procedure, using the approach of Iman and Conover (1982), which induces rank correlation in the choice of sample pairs. This technique has become standard in stratified sampling implementations. The AR4 AOGCM data also indicated that there is no significant correlation between different aggregated zones, so samples for each zone are independent of samples from the other zones.

\section{c. Economic and emissions uncertainties}

The uncertainty in the emissions of all greenhouse gases and pollutants is taken from an uncertainty analysis of the EPPA model (Paltsev et al. 2005). As discussed in Webster et al. (2002), the SRES scenarios are built on a "story line" approach, rather than emissions projections that are consistent with underlying economic, demographic, and technological assumptions for any year and over time. They are not suitable for uncertainty analysis of an economic system that results in different emissions profiles. Our approach allows a more structured development of scenarios that could serve as a basis for a story line type of analysis. Our analysis of uncertainty in economic projections is summarized only briefly here; see Webster et al. (2008) for more detail. A comparison of climate results based on our approach and the SRES scenarios is provided in Prinn et al. (2008).

Compared with previous efforts (Webster et al. 2002, 2003) several aspects of the EPPA model and of the uncertainty analysis have been improved. The technological detail of the model has been deepened, with the explicit representation of private automobiles, commercial transportation, and the service sector and the addition of biofuels as a low-carbon alternative in transportation.

The characterization of emissions coefficients for pollutants was substantially changed. We now use in the Monte Carlo analysis estimates an advancing technological frontier and catch up to this frontier by lagging regions. Statistical work by Stern $(2005,2006)$ has suggested this approach better represents the process than an approach used by Webster et al. (2002). Also, the specification of uncertainty in economic growth has been substantially revised. Rather than sampling high or low growth rates that applied to the 100 -yr horizon as has been done previously in most Monte Carlo studies of emissions, we created stochastic growth paths characterized as a random walk where the uncertainty was estimated for each region and country separately for each 5-yr EPPA period based on the economic data for years 1950-2000. As a result, regions experience periods of boom and bust over the 100-yr horizon like that which characterized growth in the latter half of the last century rather than smooth growth that was either fast or slow.

The new approach to simulating uncertainty in growth of gross domestic product (GDP) has narrowed the distribution of outcomes because regional growth rates in labor productivity are uncorrelated with each other over long periods of time. The result is that within this model the range of possible growth for individual regions is wide, but the global range is narrower as statistically rapid growth in labor productivity in some regions is likely to be offset by slow growth in other regions, based on historic data for 1950-2000. The regions of the world are also connected through international trade, so changes in economic conditions in a region do affect its major trading partners. The new approach on emissions coefficients for other pollutants results in lower median emissions of pollutants like $\mathrm{SO}_{\mathrm{x}}$, $\mathrm{NO}_{\mathrm{x}}$, and $\mathrm{CO}$.

Uncertainty in emissions were developed from the EPPA model using the same LHS approach employed here, creating a 400-member ensemble to match to match the 400-sample sets for the earth system model components (Webster et al. 2008). Each of these 400 EPPA simulations provides a set of emissions for all pollutant species that are consistent: to the extent that emissions of different species derive from the same combustion sources (e.g., oil, gas, coal) they are each consistent with the amount of fuel combusted given uncertainty in emissions per unit of fuel. Each emission set is then considered to be one emissions sample that is paired randomly with one set of values for the climate parameters following the LHS protocol of sampling without replacement.

\section{d. Design of the simulations}

The estimates of changes in climate variables presented below are obtained from the 400-member ensemble of climate change simulations with different values of the uncertain input parameters. Because of the large inertia of the ocean and carbon reservoirs, each simulation starts in 1861 and is conducted in two stages: a simulation with historical forcings and a future climate projection. During the first stage, from 1861 to 1990, the model is forced by the observed changes in GHG concentrations (Hansen et al. 2002), tropospheric and stratospheric ozone (Wang and Jacob 1998), the solar constant (Lean 2000), sulfate aerosols (Smith et al. 2004), and volcanic aerosols (Sato et al. 1993). For this stage, different sets of values of the climate sensitivity, the rates of oceanic heat and carbon uptakes, total aerosol forcing, the strength of $\mathrm{CO}_{2}$ fertilization, and changes in precipitation frequency are used in each simulation. 


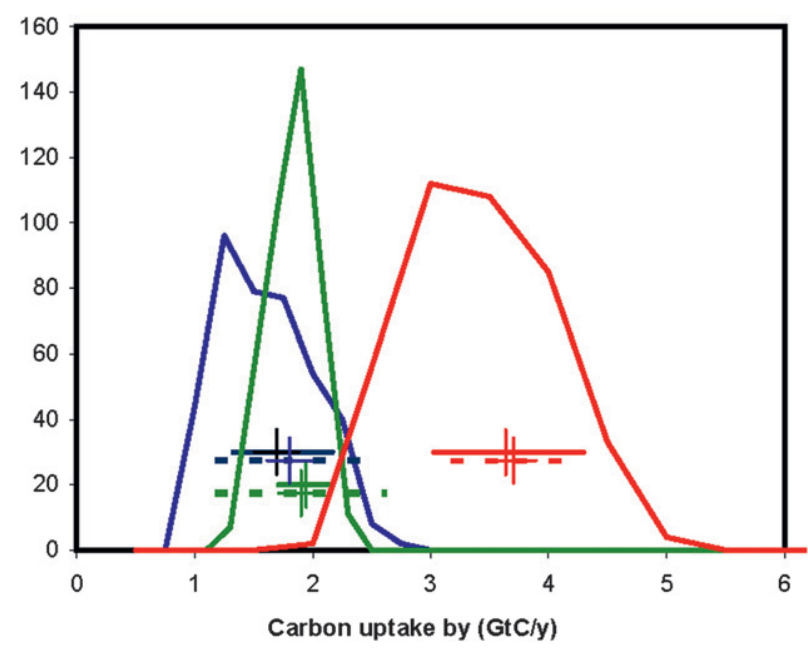

FIG. 4. Frequency distributions for carbon uptake by ocean (blue), terrestrial ecosystem (green), and total (red) averaged over the 1980s. Solid horizontal bars show 5\%-95\% ranges from $400-$ member ensemble of simulations with the MIT IGSM; dashed horizontal bars show 5\%-95\% ranges from the IPCC TAR.

To simulate changes in oceanic and terrestrial carbon stocks, the ocean carbon model and TEM are forced by the observed changes in atmospheric $\mathrm{CO}_{2}$ concentration and simulated climate. While uncertainties in ocean carbon diffusion and strength of $\mathrm{CO}_{2}$ fertilization do not affect atmospheric $\mathrm{CO}_{2}$ concentrations and associated climate during this historical period, they do affect carbon uptakes by land and ocean and, therefore, changes in corresponding carbon stocks. In the simulations described by Webster et al. (2003) carbon uptake by terrestrial ecosystem was adjusted to balance carbon cycle for the 1980s. No such adjustment is used in the present study. The resulting frequency distributions for the terrestrial, oceanic, and total carbon uptake are shown Fig. 4. Our ranges of carbon uptake by the ocean and the terrestrial ecosystem are somewhat narrower than those given in the IPCC TAR. However, the distribution for the total uptake is rather wide with a $90 \%$ range from

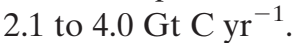

In the second stage of the simulations, which begins in 1991, the full version of IGSM2 is forced by emissions of greenhouse gases and aerosol precursors. Historical emissions are used through 1996 and emissions projected by the EPPA model from 1997 to 2100 . Emissions for years 1997, 2000, and 2005 were calculated using known values of economic growth and other EPPA parameters and agree well with observed emissions. In this future climate stage of the simulations, concentrations of all gases and aerosols are calculated by the atmospheric chemistry submodel based on anthropogenic and natural emissions and the terrestrial and oceanic carbon uptake provided by the corresponding subcom- ponents. In these simulations changes in concentration of black carbon aerosol are explicitly calculated. Since they were not considered in the preceding stage, the total aerosol forcing assumed in the first stage was adjusted to take the black carbon contribution into account. Uncertainties in the economic factors that affect anthropogenic emissions are taken into account in addition to climate-related uncertainties.

To evaluate the contributions to the total uncertainty in the projected climate changes due to the separate uncertainties in emissions and climate characteristics, we carried out two additional 400-member ensembles of simulations that each include the uncertainties from just one of these two sources. In the first set of simulations the median values of the climate parameters were used while the uncertainty in the emissions was included, and in the second the median values of the emissions were used while the uncertainty in the climate parameters was included.

\section{Twenty-first-century projections of anthropogenic climate change}

In section $4 \mathrm{a}$ we present and discuss the projections of the levels of all the important greenhouse gases and aerosols that contribute to radiative forcing of climate change. The forcing and related changes in climate are discussed in section $4 b$ together with the contributions of economic and scientific uncertainties to the uncertainty in projected climate. Changes in the biogeochemical cycles of carbon dioxide, nitrous oxide, and methane that are influenced by the joint effects of chemistry, biology, and climate change are discussed in section 4c. In section $4 \mathrm{~d}$ our projections are compared with the results of the IPCC AR4. Sensitivity of our projections to the uncertainty in the estimates of the twentieth-century changes in deep-ocean heat content are discussed in section $4 \mathrm{e}$.

\section{a. Greenhouse gas projections}

Figure 5a shows (in red) the projections of the median and $95 \%$ range for $\mathrm{CO}_{2}$ mole fractions. Compared to our earlier projections (shown in blue), the new projections are significantly higher in part because of higher projected $\mathrm{CO}_{2}$ emissions (because of changes in our approach for estimating economic uncertainties described in section 3c; see Webster et al. 2008 for more details) and in part because of changes in the oceanic and land sinks (see section $4 \mathrm{c}$ for further discussion).

For $\mathrm{CH}_{4}$, the current median projections are very similar to the previous ones but the $95 \%$ range has decreased by almost a factor of 3 (Fig. 5b). This is due in part to a lowered range in $\mathrm{CH}_{4}$ emissions (Webster et al. 

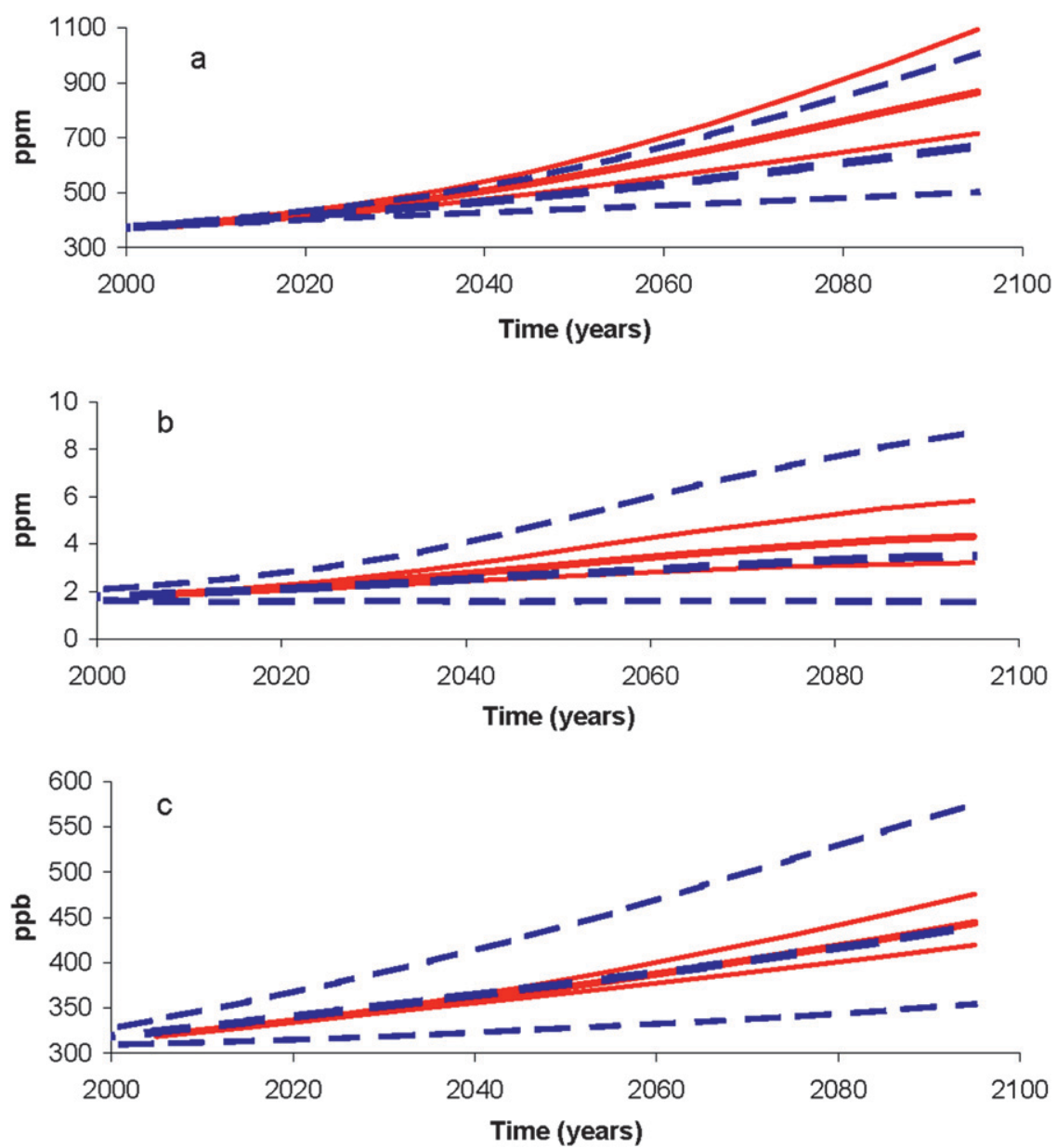

FIG. 5. Projected decadal mean concentrations of (a) $\mathrm{CO}_{2}$, (b) $\mathrm{CH}_{4}$, and (c) $\mathrm{N}_{2} \mathrm{O}$. Red solid lines are median, $5 \%$, and $95 \%$ percentiles for the present study; dashed blue lines are the same from Webster et al. (2003).

2008) but also to a decrease in the range of projected $\mathrm{OH}$ concentrations (Fig. 6b). The projected median $24 \%$ decrease in $\mathrm{OH}$ by 2100 results from the effects of the projected increases then decreases of $\mathrm{NO}_{\mathrm{x}}$, which produces $\mathrm{OH}$, being offset by the projected $\mathrm{CH}_{4}, \mathrm{CO}$, and VOC increases (all of which remove $\mathrm{OH}$ ). The projections of $\mathrm{NO}_{\mathrm{x}}, \mathrm{CO}$, and VOC concentrations are closely correlated with their emissions, which are shown in Webster et al. (2008).

For the significant greenhouse gas ozone $\left(\mathrm{O}_{3}\right)$, the projected mole fractions increase through 2050 but then decrease after that (red curves in Fig. 6a). This is driven significantly by the projected post-2050 decrease in $\mathrm{NO}_{\mathrm{x}}$. Ozone mole fractions increase the most when $\mathrm{CO}$, VOC, and $\mathrm{NO}_{\mathrm{x}}$ mole fractions all increase together, but not when $\mathrm{CO}$ and VOC increases accompany $\mathrm{NO}_{\mathrm{x}}$ decreases.

Median nitrous oxide $\left(\mathrm{N}_{2} \mathrm{O}\right)$ mole fractions are projected to increase by about $50 \%$ by 2100 (Fig. 5c) driven by increasing anthropogenic emissions and increased natural emissions induced by projected increase in soil temperature, rainfall, and soil labile carbon.

Projected mole fractions of the "industrial" gases listed in the Kyoto Protocol are shown in Fig. 7 (HFCs aggregated; PFCs aggregated; sulfur hexafluoride). The trends and uncertainties in these long-lived gases, which have very large global warming potentials (GWPs), are dominated by the trends and uncertainties in their projected emissions but augmented in the case of the HFCs by the negative trend and uncertainty in their major sink $\mathrm{OH}$ (Fig. 6b).

Figure 7 also shows projections of mole fractions of $\mathrm{SO}_{2}$, which is the precursor for sulfate aerosols and has both anthropogenic and natural (dimethyl sulfide oxidation) sources. The median and range projections are driven primarily by the projected anthropogenic emissions but augmented by the projected decrease and uncertainty in $\mathrm{OH}$, which is the principal gas-phase sink for $\mathrm{SO}_{2}$ (converting it to sulfate aerosol). 

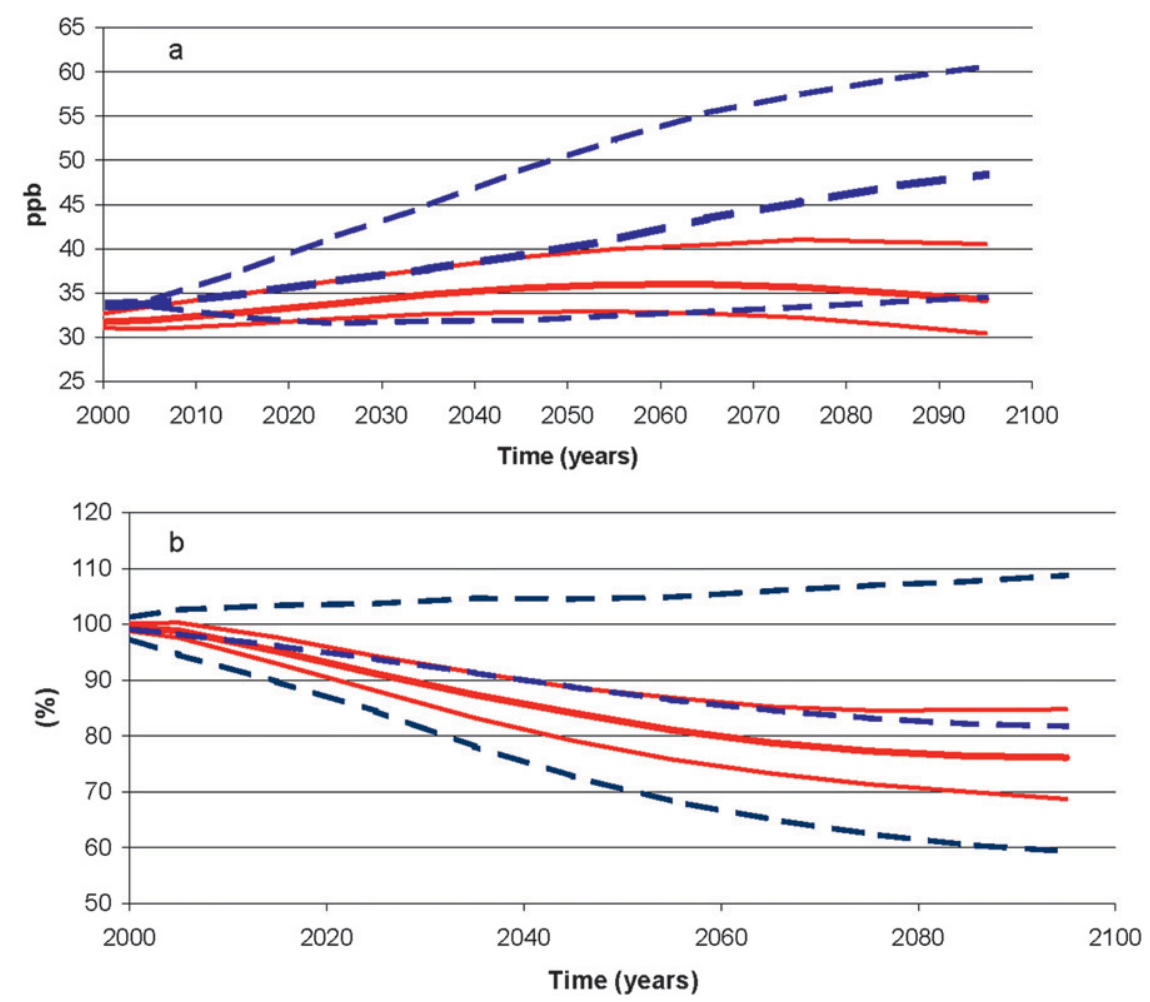

FIG. 6. Projected decadal mean concentrations of (a) ozone and (b) OH radical. The latter is shown as a ratio to its values averaged over years 1991-2000. Red solid lines are median, $5 \%$, and 95\% percentiles for the present study; dashed blue lines are the same from Webster et al. (2003).

Finally, black carbon projections are also shown in Fig. 7. Like the $\mathrm{SO}_{2}$ projections, they are driven by the anthropogenic emissions but are not affected by $\mathrm{OH}$. Their principal removal is instead through dry and wet deposition to the surface.

\section{b. Projected changes in climate}

As a result of the changes in concentrations of GHGs and sulfate and black carbon aerosols described in section $4 \mathrm{a}$, by the end of the twenty-first century radiative forcing will increase between 6.2 and $9.8 \mathrm{~W} \mathrm{~m}^{-2}$ (90\% range) compared to the year 1990 with a median increase of $7.9 \mathrm{~W} \mathrm{~m}^{-2}$ (Fig. 8a).

Changes in GHG emissions and carbon uptake lead to a significant increase of both the lower bound of the $90 \%$ range and also the median forcing compared to the results of Webster et al. (2003). The probability of the radiative forcing being less than $5.0 \mathrm{~W} \mathrm{~m}^{-2}$ is about $45 \%$ according to Webster et al. (2003) but less than $1 \%$ according to our new study. At the same time the upper bounds of the $90 \%$ ranges differ by only $0.6 \mathrm{~W} \mathrm{~m}^{-2}$ between the two studies. In fact the new upper $90 \%$ bound on the forcing due to GHGs only (Table 1) is even lower than the one in Webster et al. (2003). The slightly higher value of the upper $90 \%$ bound for the total forcing is a result of different changes in sulfate aerosol loading and the fact that forcing associated with changes in black carbon aerosol was not taken into account by Webster et al. (2003). The total forcing includes contributions from changes in GHGs, sulfate aerosol, and tropospheric ozone as well as, in present study, black carbon. As shown in section $3 b$, use of the revised probability distributions for the climate parameters leads to larger surface warming and smaller thermal expansion of the ocean for a given forcing (Fig. 3). This effect together with the differences in radiative forcing described above result in a significantly higher increase in SAT (Fig. 8b and Table 1) than was projected by Webster et al. (2003). While the upper $90 \%$ bound for surface warming projected in this study is noticeably larger than in Webster et al. (2003) $\left(7.4^{\circ} \mathrm{C}\right.$ instead of $4.6^{\circ} \mathrm{C}$ ), the changes in the lower part of the projected range are even more significant. According to Webster et al. (2003), there was a $40 \%$ probability of SAT increasing by less than $2^{\circ} \mathrm{C}$ by the end of twenty-first century relative to 1990 for the "business as usual" emissions scenario; in the present study surface warming exceeds $2^{\circ} \mathrm{C}$ in all 400 simulations. We will compare our projections of possible climate change with projections given in the IPCC AR4 in section 4d. 

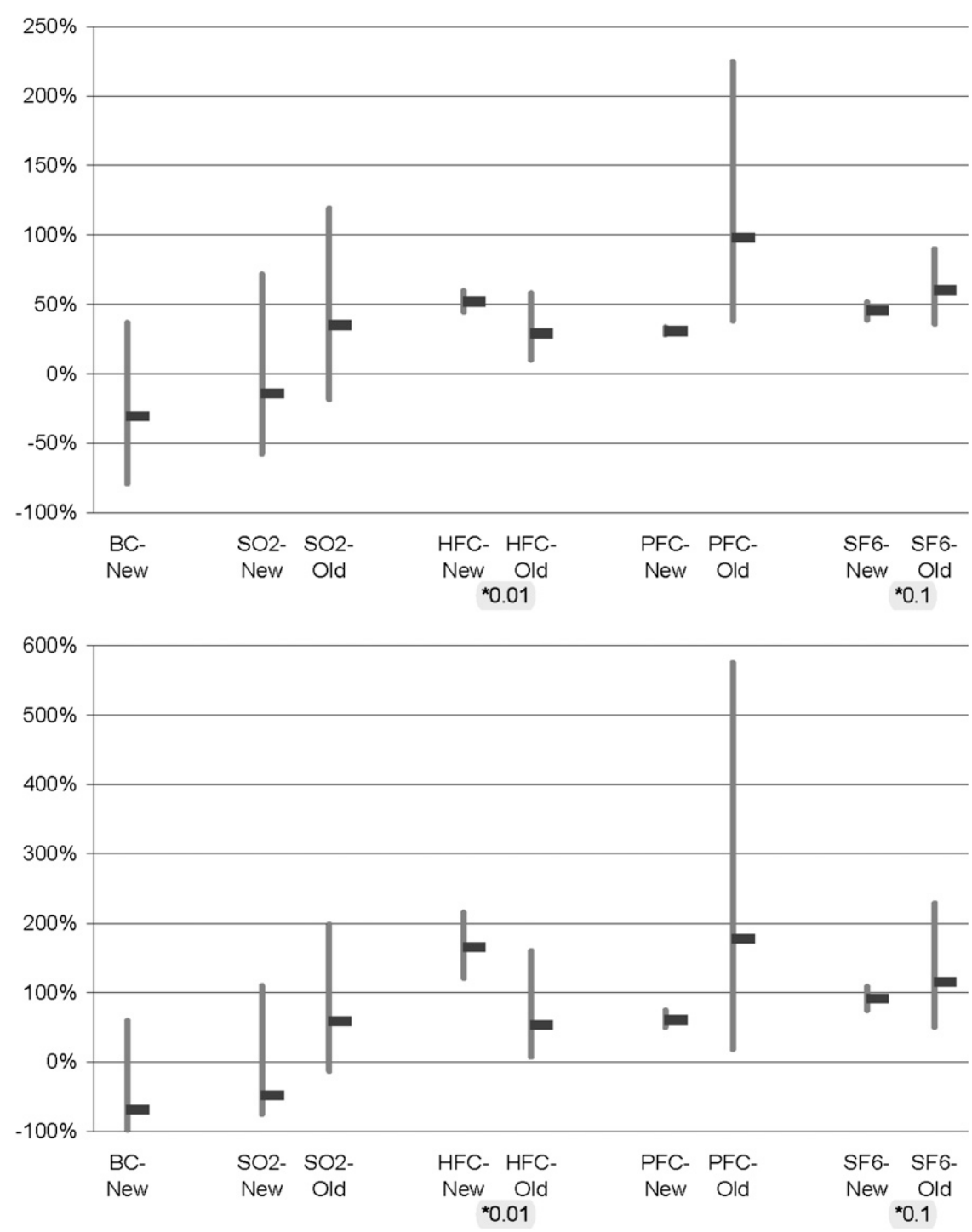

FIG. 7. Changes in concentration of some GHGs averaged over (a) 2041-50 and (b) 20912100 relative to 1991-2000 in the present study (new) and in Webster et al. (2003) (old). HFCs and SF6 are reduced by factors 100 and 10, respectively. Radiative effect of changes in the concentration of black carbon was not taken into account in Webster et al. (2003).

From the above-mentioned decrease in the thermal expansion of the ocean for a given forcing (Fig. 3b) and the similarity of the upper $90 \%$ bounds of forcing (Fig. 8a), one might expect the upper limit of the thermosteric sea level rise to be smaller in the present study than in Webster et al. (2003). However, this is not the case $^{2}$ (Fig. 8c). This apparent contradiction is explained by the changes in the ocean carbon model. As shown by Sokolov et al. (1998), the assumed dependency between

\footnotetext{
${ }^{2}$ Because of an error in the postprocessor, values of thermosteric sea level rise shown in Webster et al. (2003) are about 50\% larger than they really were.
}

rates of heat and carbon uptake by the ocean imposes a negative correlation between the rate of heat mixing into the deep ocean and the atmospheric $\mathrm{CO}_{2}$ concentration, which leads to a decrease in the uncertainty range for thermal expansion. Changes in the parameterization of oceanic carbon uptake in the current model (see section 2c and Sokolov et al. 2007) weakened this correlation, resulting in a wider range of the thermosteric sea level rise. The differences between the two studies in projected sea level rise, especially in the component related to the thermal expansion of the deep ocean, are, however, relatively smaller than the differences in projected surface temperature (Fig. 8). 

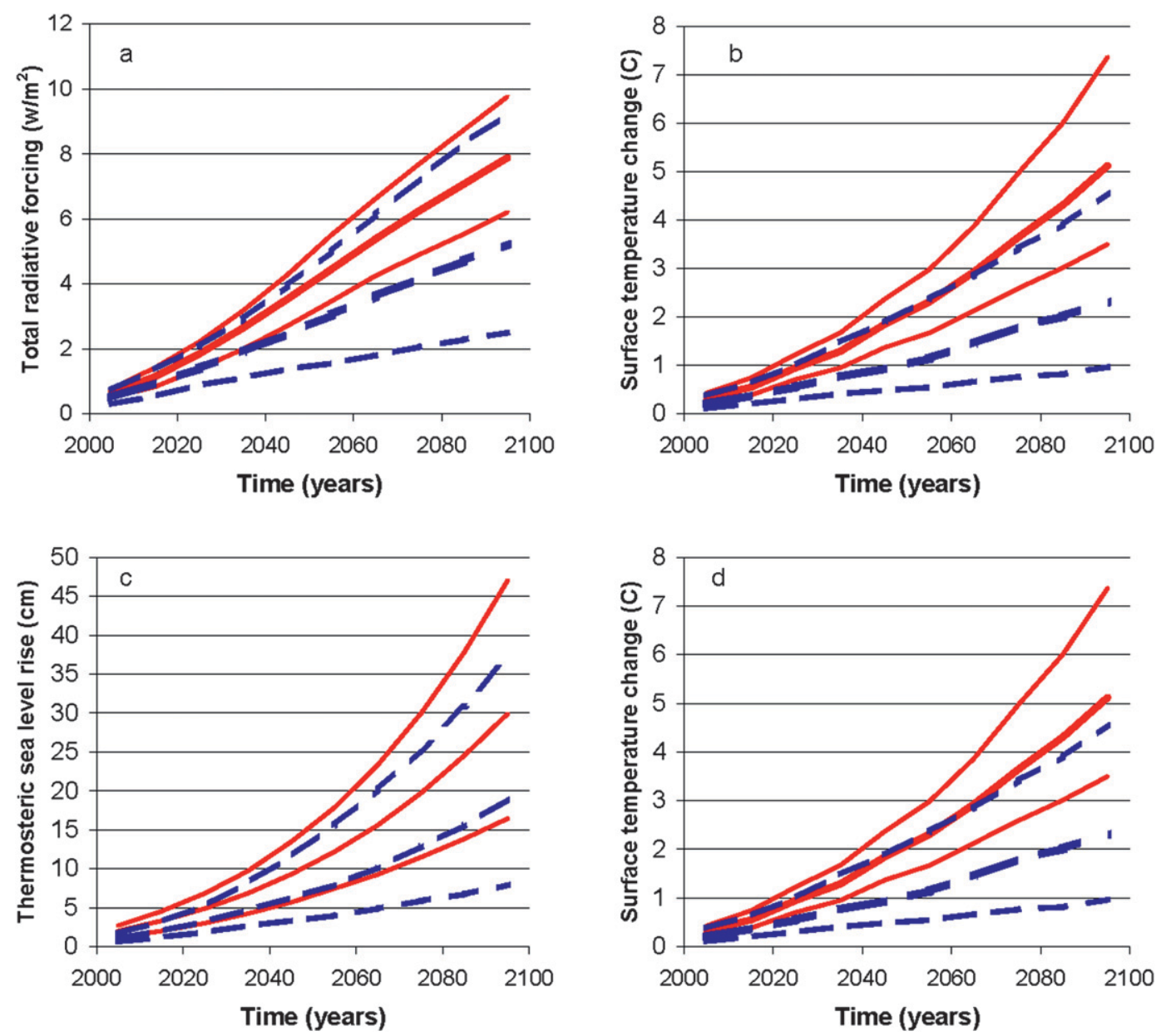

FIG. 8. Projected changes in (a) decadal mean radiative forcing due to GHGs and sulfate aerosol, (b) surface air temperature, (c) sea level rise due to thermal expansion, and (d) total sea level rise. Red solid lines are median, $5 \%$, and $95 \%$ percentiles for present study; dashed blue lines are the same from Webster et al. (2003).

The latitudinal pattern of increases in SAT (Fig. 9) is similar to those simulated by coupled AOGCMs, with polar amplification being larger in the Northern Hemisphere. Asymmetry in surface warming between the two hemispheres increases in time (Fig. 10). As can be expected, changes in SAT in polar regions are highly correlated with changes in sea ice cover (not shown). According to our simulations there is a $2 \%$ probability of the Arctic Ocean becoming ice free during summer by the end of the century. In the Southern Hemisphere the sea ice, while significantly decreasing, remains present in all simulations during the whole year. In a simulation with the median climate parameters and median emissions our model simulates a reduction of the area of Arctic sea ice by $5 \times 10^{6} \mathrm{~km}^{2}$ in wintertime and by $7 \times$ $10^{6} \mathrm{~km}^{2}$ during summer, which is about $25 \%-30 \%$ larger than the changes simulated by the AR4 AOGCMs under the A2 scenario. Unfortunately, simulations with the SRES A1FI1 scenario, which would be more compara- ble with our results (see section 4d), were not carried out with the AR4 AOGCMs. It should be noted that our model simulates rather well the observed recent changes in wintertime Arctic sea ice but significantly underestimates the summertime decline. This is not surprising since our sea ice model is purely thermodynamical, while recent changes in Arctic sea ice are attributed to an increase in sea ice transport.

As indicated in section 3d, we carried out two additional ensembles of simulations aimed at estimating the relative contributions of economics and climate uncertainties to the uncertainties in the projected climate change. As could be expected, uncertainties in atmospheric $\mathrm{CO}_{2}$ concentration and radiative forcing (Figs. 11a,b) are primarily related to the uncertainties in emissions, with a small contribution from uncertainties in the carbon uptake by land and ocean. Ignoring uncertainties in the behavior of the climate system leads to an overestimation of the lower $90 \%$ bound and the median (Fig. 11c). 
TABLE 1. Distributions of $\mathrm{CO}_{2}$ concentration, radiative forcing, changes in surface air temperature, thermosteric sea level rise, and sea level rise due to thermal expansion and glacial melt.

\begin{tabular}{|c|c|c|c|c|c|}
\hline Variable & Ensemble & Time & $5 \%$ & Median & $95 \%$ \\
\hline \multirow[t]{4}{*}{$\mathrm{CO}_{2}(\mathrm{ppmv})$} & Present study & 2045 & 495 & 533 & 574 \\
\hline & Webster et al. (2003) & & 434 & 483 & 554 \\
\hline & Present study & 2095 & 716 & 866 & 1095 \\
\hline & Webster et al. (2003) & & 502 & 670 & 1013 \\
\hline \multirow[t]{4}{*}{ Radiative forcing due to GHGs $\left(\mathrm{W} \mathrm{m}^{-2}\right.$ ) } & Present study & 2045 & 2.73 & 3.27 & 3.86 \\
\hline & Webster et al. (2003) & & 1.36 & 2.51 & 4.23 \\
\hline & Present study & 2095 & 5.98 & 7.54 & 9.40 \\
\hline & Webster et al. (2003) & & 2.33 & 5.48 & 9.80 \\
\hline \multirow[t]{4}{*}{ Total radiative forcing $\left(\mathrm{W} \mathrm{m}^{-2}\right)$} & Present study & 2045 & 2.71 & 3.53 & 4.28 \\
\hline & Webster et al. (2003) & & 1.38 & 2.47 & 3.95 \\
\hline & Present study & 2095 & 6.21 & 7.89 & 9.77 \\
\hline & Webster et al. (2003) & & 2.50 & 5.22 & 9.21 \\
\hline \multirow[t]{4}{*}{$\operatorname{SAT}\left({ }^{\circ} \mathrm{C}\right)$} & Present study & 2045 & 1.37 & 1.85 & 2.37 \\
\hline & Webster et al. (2003) & & 0.57 & 1.34 & 1.80 \\
\hline & Present study & 2095 & 3.50 & 5.12 & 7.37 \\
\hline & Webster et al. (2003) & & 1.03 & 2.37 & 4.61 \\
\hline \multirow[t]{4}{*}{ Thermosteric sea level rise $(\mathrm{cm})$} & Present study & 2045 & 6 & 9 & 14 \\
\hline & Webster et al. (2003) (1000) & & 3 & 6 & 12 \\
\hline & Present study & 2095 & 16 & 30 & 47 \\
\hline & Webster et al. (2003) (1000) & & 8 & 19 & 37 \\
\hline \multirow[t]{4}{*}{ Total sea level rise $(\mathrm{cm})$} & Present study & 2045 & 10 & 14 & 18 \\
\hline & Webster et al. (2003) & & 6 & 10 & 14 \\
\hline & Present study & 2095 & 29 & 44 & 63 \\
\hline & Webster et al. (2003) & & 15 & 29 & 50 \\
\hline
\end{tabular}

At the same time, the upper $90 \%$ bounds of the ranges of projected surface warming in both additional ensembles are similar and somewhat smaller than in the ensemble with full uncertainty, namely $7.0^{\circ} \mathrm{C}$ instead if $7.4^{\circ} \mathrm{C}$. Uncertainties in surface air temperature associated with the uncertainties of input parameters from the two different sources are rather similar (see Table 2). The probability of extreme changes increases because of the conjunctions of uncertainties from two independent sources.

In the case of sea level rise (Fig. 11d), the situation is rather different. Namely, uncertainties in the sea level rise due to thermal expansion of the deep ocean are primarily associated with the uncertainties in the climate parameters. This is explained by the large thermal inertia of the ocean, which significantly delays its response to changes in radiative forcing. Sokolov et al. (2007) carried out climate change simulations for three different combinations of climate parameters and two very different emissions scenarios. Their simulations showed that thermal sea level rise has practically no dependence on forcing through the year 2050. Even at the end of the twenty-first century, sea level rise is more sensitive to changes in characteristics of the climate system than in emissions. Such behavior was also observed in simulations with the version of the IGSM2 in which a 3D ocean GCM was used instead of a 2D anomaly-diffusing ocean model. Of course the impact of uncertainties in anthropogenic emissions on uncertainties in projected sea level rise will be much larger on longer time scales.

\section{c. Changes in carbon fluxes}

In addition to examining the statistical analysis of the model runs, it is instructive to examine a subset of runs in greater detail. Changes in global surface average temperature result from a combination of emissions and climate parameters, and therefore two runs that look similar in terms of temperature may be very different in detail. In this section four runs (Table 3 ) are examined in greater detail, especially in regards to fluxes of the major GHGs. A pair of scenarios was chosen from the $95 \%$ upper bound of surface temperature change (scenarios $\mathrm{C}$ and $\mathrm{D}$ ), and the other pair was chosen from the $5 \%$ lower bound of surface temperature change (scenarios A and B). In each pair, one scenario had higher climate sensitivity but lower GHG concentrations than the other scenario with equivalent temperature (Table 3). High concentrations of different gases tend to be correlated with each other, as anthropogenic emissions of all these gases are driven by many of the same underlying factors such as economic growth rates (Webster et al. 2008).

Concentrations of GHGs in the atmosphere are a function of sources and sinks. Anthropogenic emissions are the primary driver of changing GHG concentrations, 


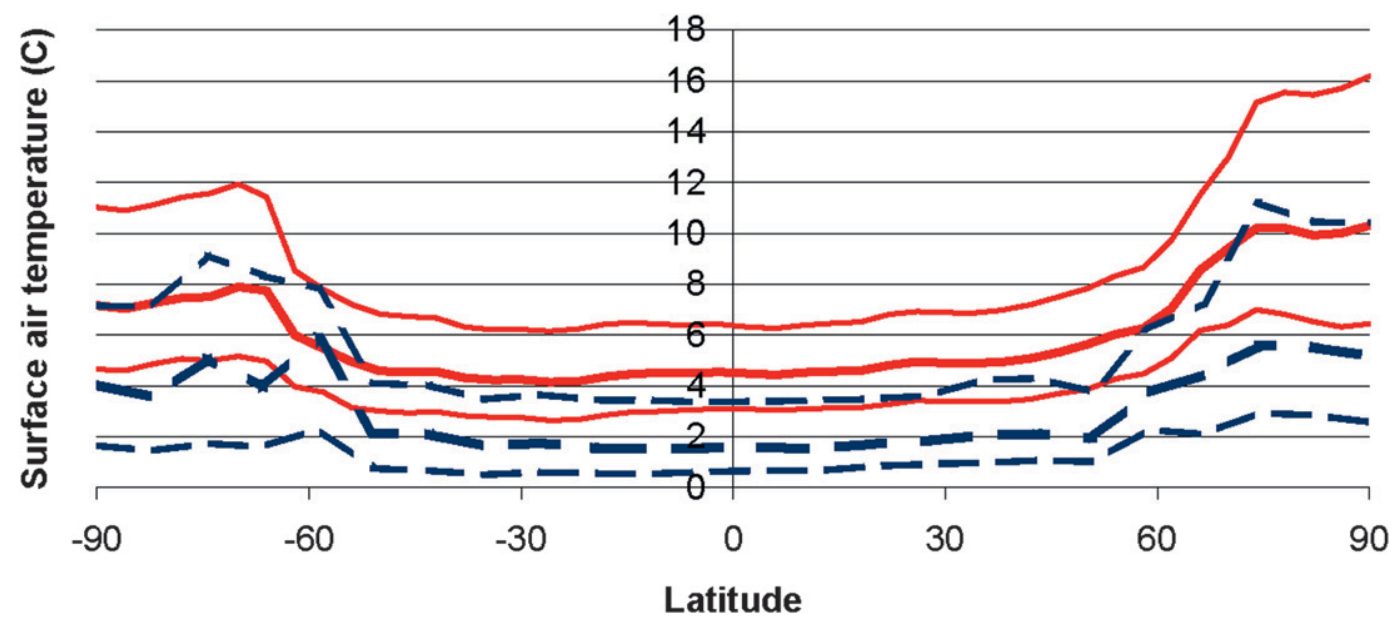

FIG. 9. Latitudinal distribution of changes in SAT in the last decade of the twenty-first century relative to 19812000. Red solid lines are median, $5 \%$, and $95 \%$ percentiles for the present study; dashed blue lines are the same from Webster et al. (2003).

but there are also natural sources of $\mathrm{N}_{2} \mathrm{O}$ and $\mathrm{CH}_{4}$, mainly in terrestrial wetlands. There are a number of sinks involved for the three major GHGs-ecosystems, oceans, atmospheric chemistry, and stratospheric disassociation. Most of the nonanthropogenic sinks and sources are functions of temperature, precipitation, and chemical or radiative interactions with other emissions, and these interactions are examined in more detail in this section.
As discussed by Sokolov et al. (2008), the terrestrial ecosystem response to increased $\mathrm{CO}_{2}$ concentrations is limited by nitrogen availability. However, surface warming leads to an increase in carbon uptake as the resulting increased soil matter decomposition releases nitrogen, thereby allowing the ecosystem to take advantage of the higher $\mathrm{CO}_{2}$ levels. However, when surface air temperature exceeds a critical value, increase in respiration may

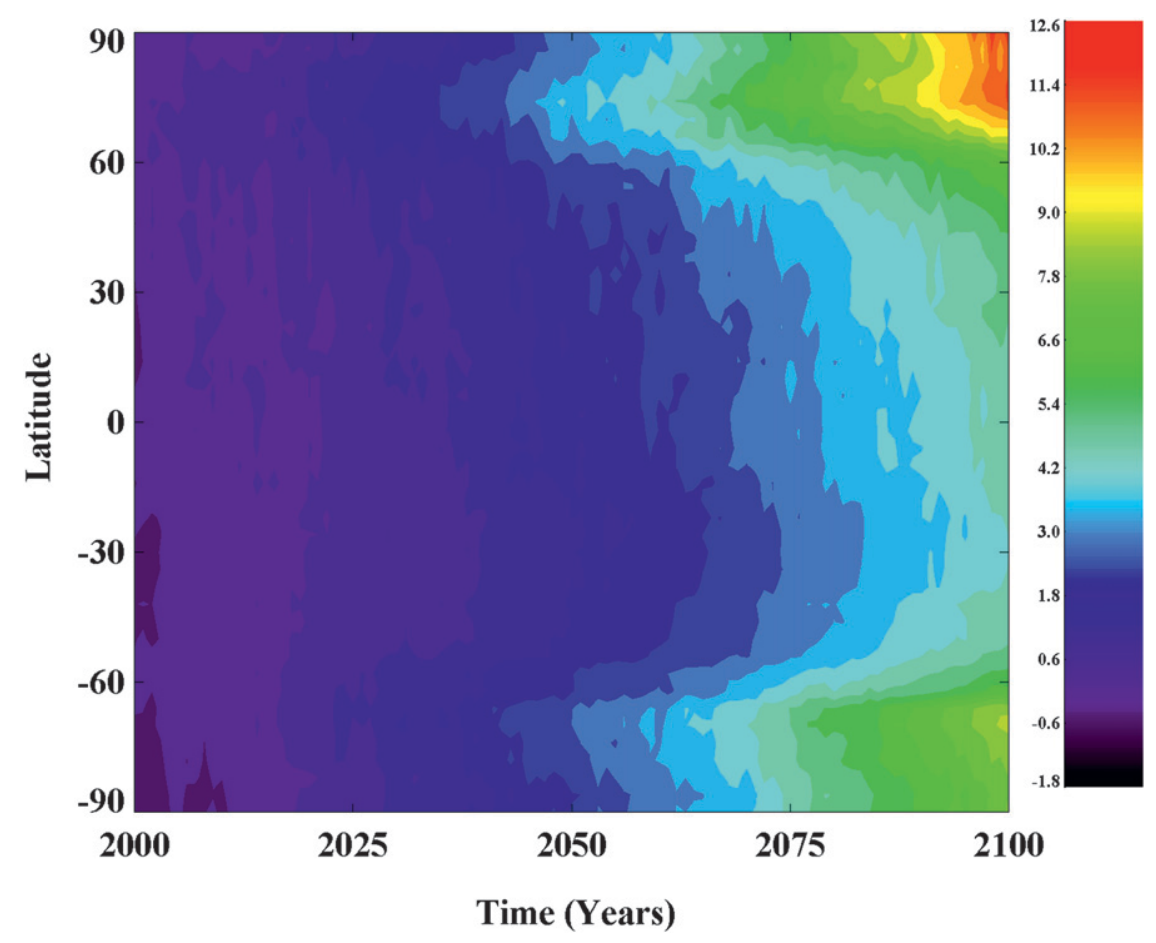

FIG. 10. Transient change in surface air temperature in simulation with median values of parameters for both economics and climate models. 

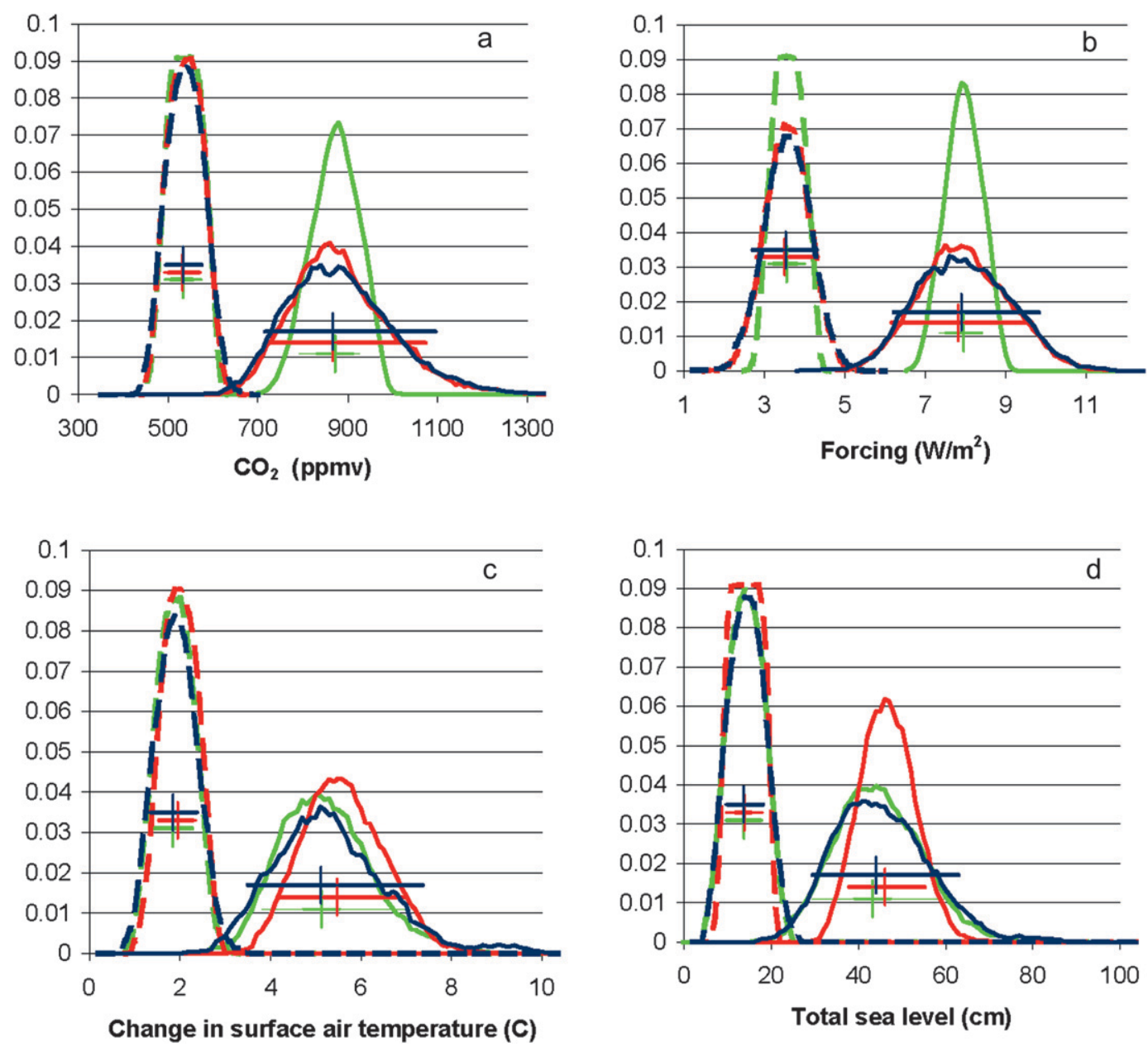

FIG. 11. Frequency distributions for (a) atmospheric $\mathrm{CO}_{2}$ concentrations, (b) radiative forcing due to GHGs and sulfate aerosol, (c) surface air temperature, and (d) total sea level rise in simulations with full uncertainty (blue), climate uncertainty (green), and emissions uncertainty (red) averaged over 2041-50 (dashed lines) and 2091-2100 (solid lines).

overcome increase in gross primary productivity resulting in the decrease of net terrestrial carbon uptake. The critical value of SAT depends on changes in atmospheric $\mathrm{CO}_{2}$ concentration and the value of the half-saturation constant $(k c)$. For example, in case $\mathrm{D}$ terrestrial uptake peaks at $3 \mathrm{Gt} \mathrm{C} \mathrm{yr}^{-1}$ near year 2080 and starts to decrease after increases in SAT exceeds $5.5^{\circ} \mathrm{C}$ (Fig. 12). At the same time, in scenario $\mathrm{C}$, despite similar surface warming, terrestrial carbon uptake increases through the whole simulation because of large values of $k c$ used in this simulation and a larger increase in the atmospheric $\mathrm{CO}_{2}$ concentration. In some of the hottest cases the terrestrial ecosystem becomes a net carbon source during the last decade of twenty-first century. In all four cases, carbon uptake by the terrestrial ecosystem is rather significant, on the order of $15 \%-20 \%$ of anthropogenic emissions-cumulative uptake ranges from $215 \mathrm{Gt} \mathrm{C}$ in scenario B to $350 \mathrm{Gt}$ C in scenario C.
Ocean uptake is the other major $\mathrm{CO}_{2}$ sink. Section $2 \mathrm{~d}$ discusses how the carbon sink in IGSM2.2 is calibrated to reproduce the behavior of the three-dimensional ocean. One of the important results of this calibration is that the end of century uptake is significantly lower than it would be in the version of the simplified carbon model used by Webster et al. (2003). In all four runs ocean uptake peaks in midcentury and begins to decrease despite the continuing increases in atmospheric $\mathrm{CO}_{2}$ concentration. However, the ocean still takes up a cumulative total of $300 \mathrm{Gt} \mathrm{C}$ (scenario C) to $470 \mathrm{Gt} \mathrm{C} \mathrm{(scenario} \mathrm{B).}$

The NEM controls the emissions of methane and $\mathrm{N}_{2} \mathrm{O}$ into the atmosphere. As precipitation and temperature increase it is expected that natural emissions of both substances will also increase, but the exact nature of these increases depends on timing of precipitation events. High-latitude regions (north of $50^{\circ} \mathrm{N}$ ) exhibit a somewhat larger flux increase than the remainder of the 
TABLE 2. Ratios of the percentiles to mean values for distributions of surface warming and sea level rise at the last decade of the twenty-first century in ensembles with full, climate, and emission uncertainties.

\begin{tabular}{lccccc}
\hline \hline \multicolumn{1}{c}{ SAT } & $5 \%$ & $16.7 \%$ & $50 \%$ & $83.3 \%$ & $95 \%$ \\
Full uncertainty & 0.66 & 0.78 & 0.97 & 1.22 & 1.40 \\
Climate uncertainty & 0.74 & 0.82 & 0.99 & 1.17 & 1.35 \\
Emission uncertainty & 0.75 & 0.85 & 0.99 & 1.16 & 1.25 \\
$\quad$ & & & & & \\
$\quad$ Sea level rise & $5 \%$ & $16.7 \%$ & $50 \%$ & $83.3 \%$ & $95 \%$ \\
Full uncertainty & 0.64 & 0.76 & 0.98 & 1.24 & 1.43 \\
Climate uncertainty & 0.67 & 0.80 & 0.98 & 1.20 & 1.36 \\
Emission uncertainty & 0.82 & 0.88 & 1.00 & 1.12 & 1.19 \\
\hline
\end{tabular}

globe, especially in the hot scenarios $(\mathrm{C}$ and $\mathrm{D})$ where northern latitude emissions (green dashed line in Fig. 13) increase by more than $70 \%$ while the flux from the remainder of the planet increases by only $33 \%$ and $24 \%$.

Increased methane emissions are also expected to be prevalent in high-latitude regions (north of $50^{\circ} \mathrm{N}$ ) because of the thawing of permafrost and increased $\mathrm{CO}_{2}$ fertilization of plants (Zhuang et al. 2006). In the two warm runs high-latitude emissions of methane increase by more than $150 \%$ (Fig. 14, dotted green lines) compared to increases in the remainder of the planet of about $35 \%$. Cumulatively, more than $3000 \mathrm{Tg}$ of additional methane due to increased high-latitude emissions are released into the atmosphere in both of the warm runs. This release of methane only accounts for a small fraction of the carbon stored in the soils of these highlatitude regions, and emissions can be expected to continue to increase significantly after 2100 .

Methane concentrations are also a function of the atmospheric sink, mainly the hydroxyl free radical. As $\mathrm{CO}$ and $\mathrm{CH}_{4}$ emissions increase, the hydroxyl radical concentrations will drop as seen in section 4a. When $\mathrm{OH}$ levels drop, the $\mathrm{CH}_{4}$ sink will decrease and methane lifetime will increase. This impact on $\mathrm{CH}_{4}$ levels can be roughly estimated by plotting methane concentrations in the hypothetical case where lifetime does not decrease (Fig. 14, dashed purple line). In both the hot scenarios $(\mathrm{C}$ and $\mathrm{D})$ the cumulative sink decrease over the century is equivalent to about $12 \cdot 10^{3}$ teragrams of methane emissions.

\section{d. Comparison with the IPCC AR4 projections}

As discussed in the introduction, the treatment of uncertainty in anthropogenic emissions in this study is fundamentally different from that by the IPCC. The climate simulations described in the IPCC AR4 (Meehl et al. 2007a) were carried out for several distinctly different emission scenarios, either assuming "business as usual" economic activities (A2, A1FI) or aimed at atmospheric $\mathrm{CO}_{2}$ stabilization at a particular level (A1B
TABLE 3. Values of climate parameters and values of some climate variables averaged over last decade of the twenty-first century for the simulations discussed in section $4 \mathrm{c}$.

\begin{tabular}{ccccccccc}
\hline \hline & $C_{S}$ & $K_{v}$ & $F_{\text {aer }}$ & $K_{c}$ & $\mathrm{SAT}$ & $\mathrm{CO}_{2}$ & $\mathrm{CH}_{4}$ & $\mathrm{~N}_{2} \mathrm{O}$ \\
\cline { 2 - 8 } Scenario & ${ }^{\circ} \mathrm{C}$ & $\mathrm{cm}^{2} \mathrm{~s}^{-1}$ & $\mathrm{w} \mathrm{m}^{-2}$ & $\mathrm{ppm}$ & ${ }^{\circ} \mathrm{C}$ & $\mathrm{ppm}$ & $\mathrm{ppm}$ & $\mathrm{ppb}$ \\
\hline $\mathrm{A}$ & 1.83 & 0.22 & -0.46 & 350 & 3.68 & 885 & 4.15 & 440.16 \\
$\mathrm{~B}$ & 3.75 & 3.21 & -0.65 & 384 & 3.70 & 622 & 3.3 & 413.38 \\
$\mathrm{C}$ & 2.55 & 0.10 & -0.59 & 468 & 7.49 & 1108 & 5.44 & 450.83 \\
$\mathrm{D}$ & 4.10 & 0.96 & -0.58 & 196 & 7.49 & 886 & 4.15 & 444.75 \\
\hline
\end{tabular}

and B2). However, no probabilities were associated with these different emissions scenarios. Uncertainties in the climate response for a given emission scenario were associated only with uncertainty in the characteristics of the climate system (Meehl et al. 2007a; Knutti et al. 2008). Therefore the IPCC AR4 results should be compared with the results of our ensemble of simulations in which only climate uncertainty was included while GHG emissions were calculated using median values of the uncertain economic parameters (see section 3d).

The cumulative carbon emissions produced by the EPPA model with these parameter values are very similar to those for the A2 scenario and somewhat smaller than those in the A1FI scenario (see Fig. 15a). However, the atmospheric $\mathrm{CO}_{2}$ concentration obtained in the simulation with the IGSM using the median values of both the emission and climate parameters is closer to the concentration in the A1FI scenario (Fig. 15b). This is explained, at least partly, by the fact that the terrestrial ecosystem model used in the IGSM2, in contrast to the Integrated Science Assessment Model (ISAM) model used to calculate $\mathrm{CO}_{2}$ concentrations for the SRES scenarios, considers carbon-nitrogen interactions. As shown by Sokolov et al. (2008), taking into account the nitrogen limitation on terrestrial carbon uptake leads to a large increase in atmospheric $\mathrm{CO}_{2}$ for given carbon emissions. The forcings due to individual GHGs $\left(\mathrm{CH}_{4}\right.$, $\mathrm{N}_{2} \mathrm{O}$, etc.) are somewhat different for our median emission scenario and for A1FI, but the total forcings are quite similar (Fig. 15c). Thus it is appropriate to compare our results for the ensemble of simulations including only the climate model uncertainties with the IPCC's projections for the A1FI scenario.

Since the AR4 AOGCMs did not simulate the A1FI scenario, the IPCC calculated the mean value of SAT increase for the A1FI scenario from 19 simulations with the simple climate model (SCM) Model for the Assessment of Greenhouse-Gas Induced Climate Change, version 4 (MAGICC4; Wigley and Raper 2001). The 19 different versions of the SCM were each tuned to simulate the behavior of a different one of the 19 AOGCMs used in the IPCC AR4 (Meehl et al. 2007a). The mean of 

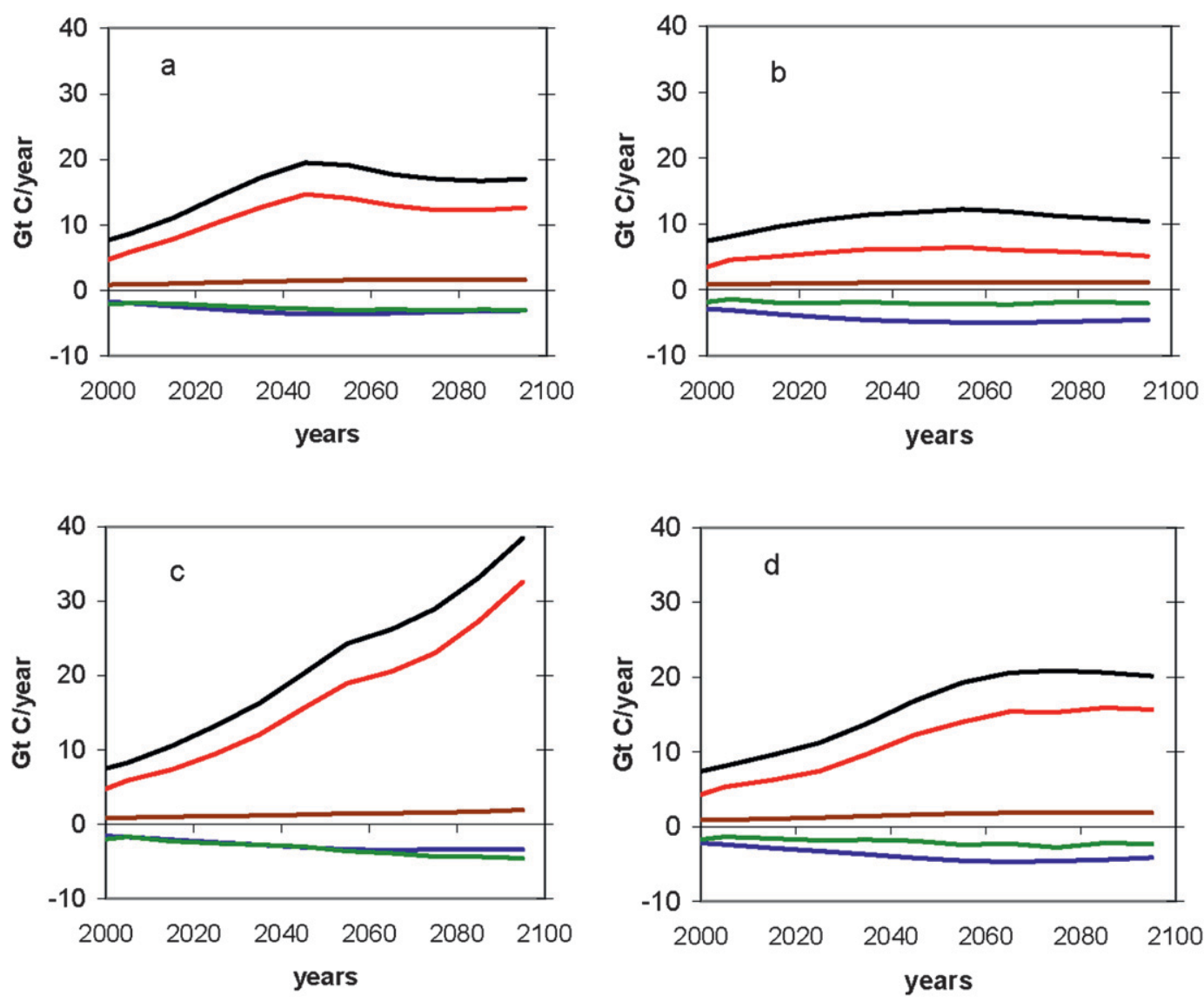

FIG. 12. Carbon fluxes in gigatons of carbon per year. Black: anthropogenic $\mathrm{CO}_{2}$ emissions. Green: terrestrial sink. Blue: ocean sink. Brown: $\mathrm{CO}$ and $\mathrm{CH}_{4}$ emissions. Red: change in atmospheric burden.

the 19 SCM simulations was scaled to allow for a small bias in the SCM compared to the AOGCMs simulations for other scenarios (Meehl et al. 2007a; Knutti et al. 2008). Because, as noted by Meehl et al. (2007a), AOGCMs do not sample the full range of possible warming, the IPCC AR4's projected likely range (Solomon et al. 2007) of warming is not based solely on the 19 simulations but was estimated with the help of results of additional studies (Knutti et al. 2008), including simulations with models of intermediate complexity. Some of the models of intermediate complexity in addition to uncertainties in climate sensitivity, rate of oceanic heat uptake, strength of aerosol forcing, and carbon cycle consider uncertainty in the feedback between the carbon cycle and climate (e.g., Knutti et al. 2003). Thus the likely range of warming was judged to extend from $40 \%$ less to $60 \%$ more than the mean SAT increase (Meehl et al. 2007a; Knutti et al. 2008). We note that, according to the IPCC AR4 definition, the probability of SAT change falling into the likely range is more than $66 \%$ but less than $90 \%$.

Table 4 compares the IPCC's mean and likely range of SAT increase for the A1FI scenario with those based on the results of the simulations with the latest version of the SCM MAGICC6 (Meinshausen et al. 2008), tuned to 19 AR4 AOGCMs, and with those from our simulations with median anthropogenic emissions. ${ }^{3}$

As discussed by Sokolov et al. (2009), the AR4 multimodel ensemble underestimates surface warming compared to MIT simulations with input parameter distributions obtained using Levitus et al. (2005) data on changes in deep-ocean heat content. The same, of course, is true for the SCM MAGICC. In particular, our mean SAT increase is $30 \%$ greater than the IPCC's $5.2^{\circ} \mathrm{C}$ versus $4.0^{\circ} \mathrm{C}$. The uncertainty range obtained in

\footnotetext{
${ }^{3}$ The uncertainty range for simulations with the SCM MAGICC4 is significantly wider than the range for the AR4 AOGCMs. For example, the \pm standard deviation range obtained in simulations with the SCM MAGICC4 for fixed carbon cycle for the SRES A2 scenario is almost identical to the $5 \%-95 \%$ range for the AR4 AOGCMs for the same scenario (Knutti et al. 2008). This disagreement is likely explained by the fact that MAGICC4 was tuned to a different set of AOGCMs than that used in the IPCC AR4 simulations.
} 

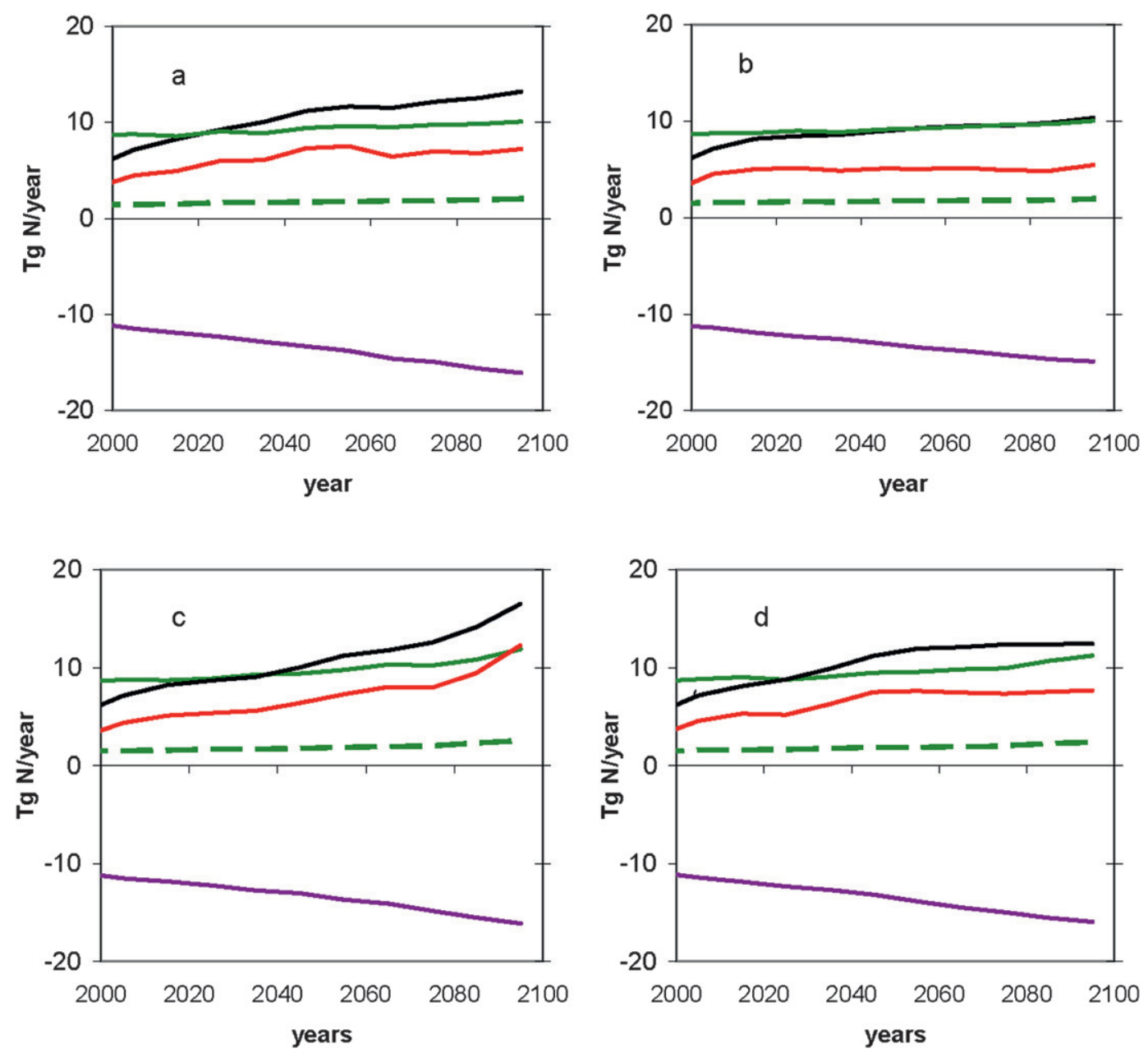

FIG. 13. $\mathrm{N}_{2} \mathrm{O}$ fluxes in $\mathrm{Tg} \mathrm{N} \mathrm{yr}^{-1}$. Black: anthropogenic emissions. Green: natural emissions. Dashed green: northern latitude emissions. Purple: stratospheric sink. Red: change in atmospheric burden.

the MIT simulations is narrower and somewhat more symmetric than the ranges given by the IPCC and obtained in simulations with SCM MAGICC6; that is, the lower bound of the $90 \%$ range is smaller than the mean by $26 \%$, while the upper bound is larger by $35 \%$ (Table 5 ). The asymmetry in the IPCC and MAGICC6 ranges is, to a large extent, associated with the uncertainty in the carbon cycle-climate feedback. As indicated by Knutti et al. (2008), inclusion of the uncertainty in carbon cycleclimate feedback as simulated by the Coupled ClimateCarbon Cycle Model Intercomparison Project ( $\left.{ }^{4} \mathrm{MIP}\right)$ models (Friedlingstein et al. 2006) extends the projected range of surface warming, with larger effect on the upper bound. In contrast with all models used by the IPCC the MIT IGSM takes into account the carbon-nitrogen interaction in the terrestrial ecosystem. As was shown by Sokolov et al. (2008), considering this interaction significantly reduces the strength of the feedback between the carbon cycle and climate and the uncertainty in the projected $\mathrm{CO}_{2}$ concentration and surface warming associated with this feedback.

\section{e. Sensitivity of the projected surface warming to the deep-ocean data used to derive climate input parameters}

Sokolov et al. (2009) compared results of ensembles of projections with the climate component of the MIT IGSM carried out using distributions of climate input parameters obtained with different data for changes in deep-ocean heat content. As noted in the introduction, for the comparison with our previous results (Webster et al. 2003), we decided to use climate parameter distributions based on the Levitus et al. (2005) data in our simulations. We refer to these distributions as the LEV05 distributions. However, results presented by Sokolov et al. (2009) allow us to approximate the distribution of changes in SAT for different climate parameter distributions without running a full ensemble of 

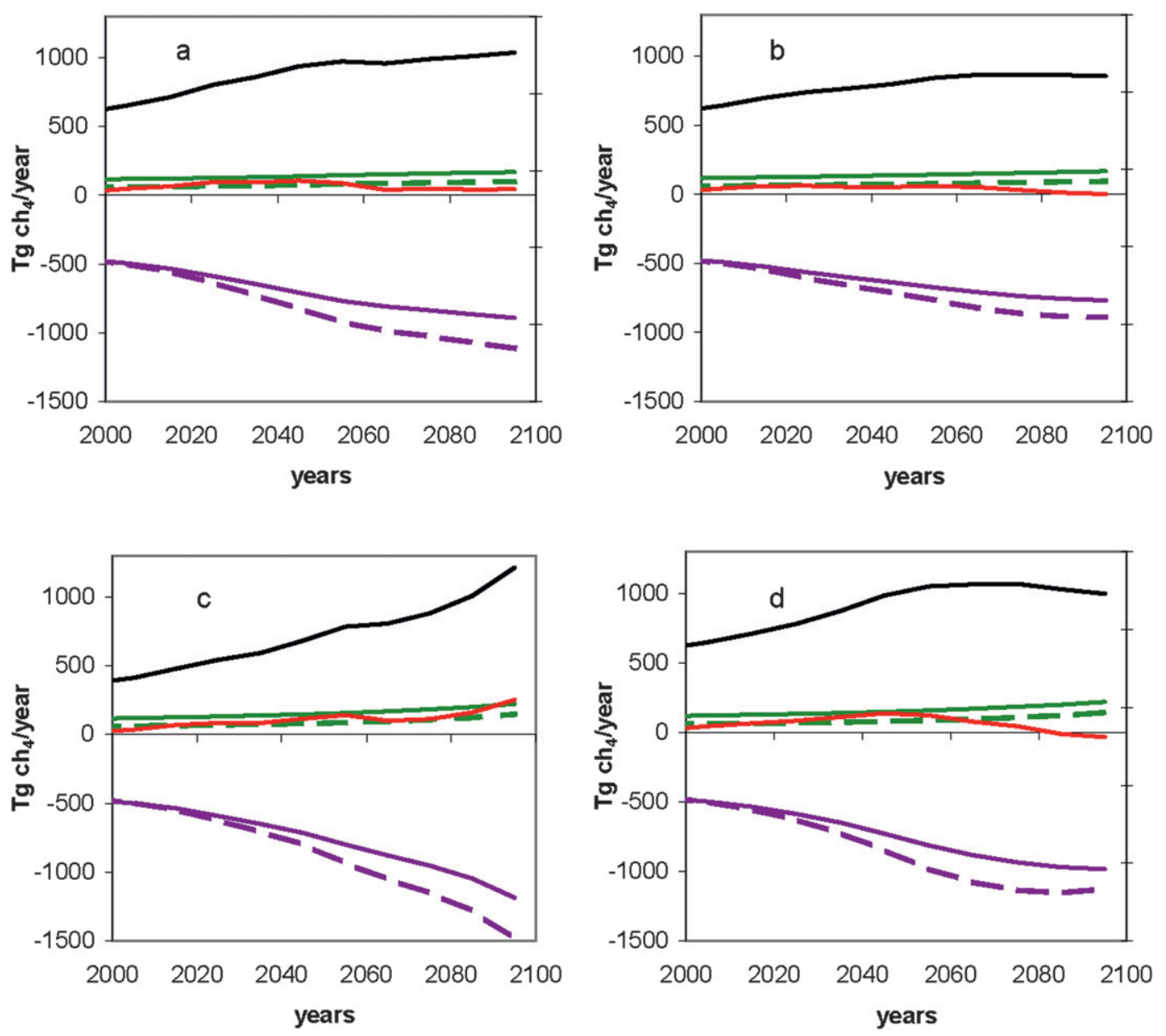

FIG. 14. Methane fluxes in $\mathrm{Tg} \mathrm{CH}_{4} \mathrm{yr}^{-1}$. Black: anthropogenic emissions. Red: change in atmospheric burden. Green: natural emissions. Dashed green: northern latitude emissions. Purple: methane sink. Dashed purple: constant lifetime counterfactual sink.

simulations. In this section we show how our results would have changed if we had used input distributions for climate parameters based either on Domingues et al. (2008) or on upper- and surface-air temperatures only, DOM08 and NO, respectively. We note that the LEV05 and DOM08 analyses give, respectively, the smallest and largest published estimates of the heat uptake (Sokolov et al. 2009).

As can be seen from the Sokolov et al. (2009), the shapes of the distributions for changes in SAT in the simulations with different distributions of climate input parameters are similar. In other words, ratios of the percentile values to the means do not differ significantly for ensembles with different input climate parameters (see Table 6 in Sokolov et al. 2009). This similarity between output distributions may be explained by the fact that projected surface warming is defined by joint input distributions, which are constrained by the same data on SAT changes over the twentieth century. Based on that, an estimate of the probability distribution for changes in SAT for a particular input distribution can be constructed by scaling the output distribution from the ensemble of simulations, carried out with different input distribution, by the ratio of the SAT changes in the simulations with the median values of input climate parameters from the two input distributions. Table 6 shows the alternative distributions for cases with climateonly uncertainty and full uncertainty.

For both uncertainty cases, the mean value of surface warming in the last decade of the twenty-first century decreases by about $0.3^{\circ} \mathrm{C}$ for the $\mathrm{NO}$ and $1.2^{\circ} \mathrm{C}$ for the DOM08 climate parameter distributions. Thus the DOM08 case has a mean warming very close to the IPCC's projection. In the simulations with full (climate only) uncertainties, the probability for an SAT increase exceeding $6.4^{\circ} \mathrm{C}$ by the end of the century decreases from $17 \%$ (12\%) for LEV05 to $2.7 \%$ (0.5\%) for DOM08 input climate distributions. The probability of surface 

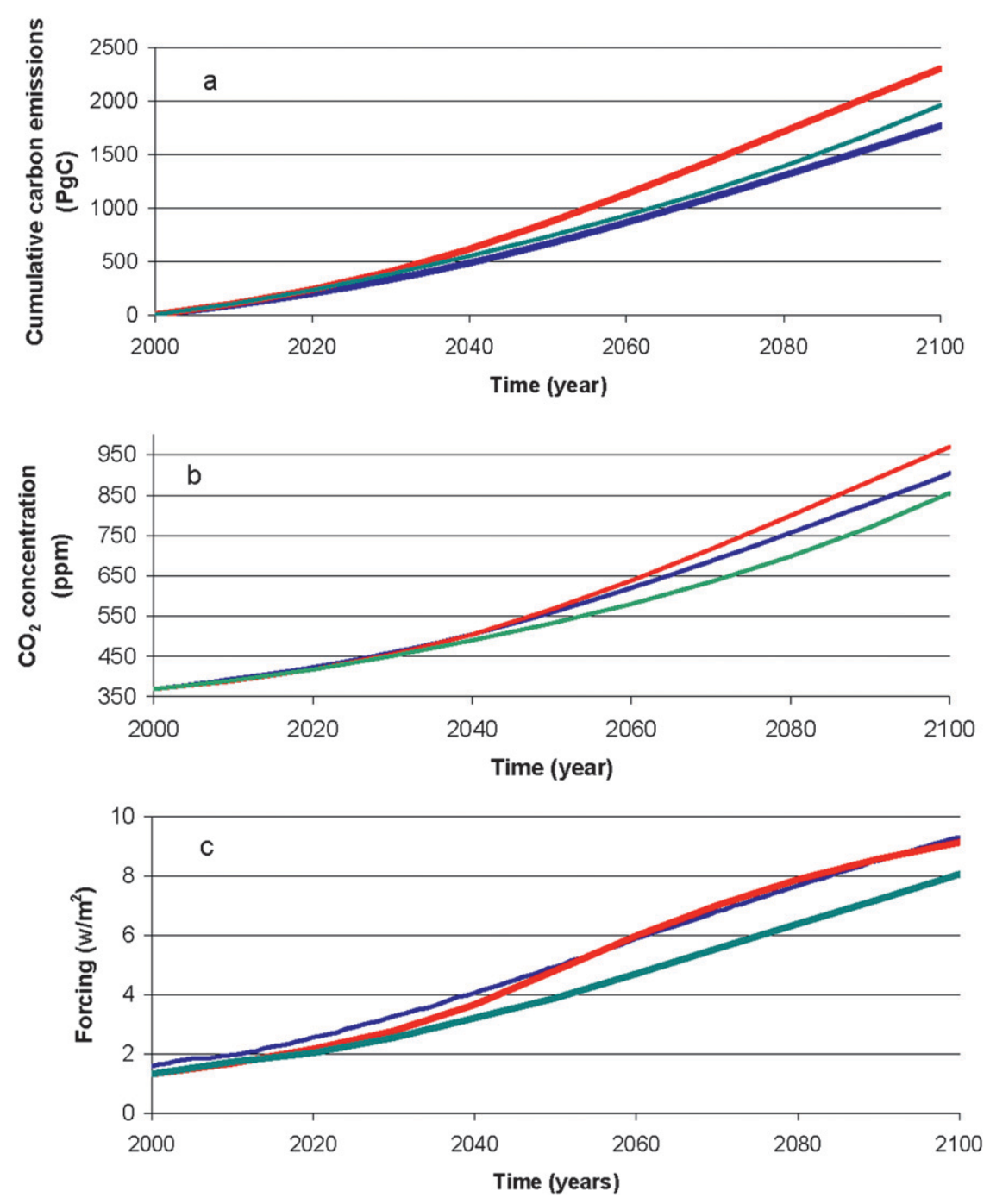

FIG. 15. (a) Cumulative carbon emissions, (b) atmospheric $\mathrm{CO}_{2}$ concentration, and (c) radiative forcing due to greenhouse gases and aerosol for SRES scenarios A1FI (red) and A2 (green) and for MIT simulation (blue) with the IGSM using median values for climate input parameters and median GHG emissions.

warming being less than $2.4^{\circ} \mathrm{C}$ is about $2.8 \%$ and $1.2 \%$ for the DOM08 distribution for the full and climate-only uncertainty cases, respectively. For the LEV05 distributions SAT increases by more than $2.4^{\circ} \mathrm{C}$ in all simulations for either uncertainty case. According to the IPCC AR4 projections the probability of SAT increase larger than $6.4^{\circ} \mathrm{C}$ or smaller than $2.4^{\circ} \mathrm{C}$ for the A1FI scenario is estimated as being between $5 \%$ and $16.7 \%$. The much smaller likelihood we find for modest warming is likely due to our input pdfs having been explicitly constrained by twentieth-century temperature changes.

Projections of sea level rise due to thermosteric expansion are much more sensitive to the ocean data used than are the projections of SAT (Sokolov et al. 2009). However, probability distributions for sea level rise cannot be constructed using the scaling approach described above.

The comparisons just discussed do not per se tell us which of the three different projections compared in Table 6 is best. We note that the results based on LEV05 and DOM08 each used the error estimates given by the respective analyses as being appropriate for their estimates of the trend in ocean warming. However, these estimates are mutually incompatible. The DOM85 trend is more than double the LEV05 trend, but the difference between the two trends is 5-7 times the standard deviation in the trend cited by the respective analyses. All this emphasizes an urgent necessity for obtaining more definite estimates for changes in deep-ocean heat content. 
TABLE 4. Change is SAT at the last decade of the twenty-first century relative to 1981-2000, at year 2100 for MAGICC6 Meinshausen et al. (2008).

\begin{tabular}{|c|c|c|c|c|c|}
\hline & $5 \%$ & $16.7 \%$ & Mean & $83.3 \%$ & $95 \%$ \\
\hline MIT simulations with median anthropogenic emissions & 3.81 & 4.22 & 5.17 & 6.04 & 6.98 \\
\hline $\begin{array}{l}\text { SCM MAGICC6 Meinshausen et al. (2008) } \\
\text { (with uncertainty in feedback between climate and carbon cycle) for SRES A1FI }\end{array}$ & 2.85 & 3.26 & 4.09 & 4.79 & 5.88 \\
\hline SCM MAGICC4 (with carbon uptake uncertainty) for SRES A1FI & - & 3.3 & 4.4 & 5.8 & - \\
\hline IPCC AR4 for SRES A1FI & \multicolumn{2}{|r|}{2.4} & 4.0 & \multicolumn{2}{|c|}{6.4} \\
\hline
\end{tabular}

\section{Conclusions}

In this paper we have presented updated projections of climate changes for the twenty-first century in the absence of any climate policy. While the MIT IGSM has been significantly modified since publication of our previous projections (Webster et al. 2003), the primary reasons for the differences between our previous and present results are changes in the distributions of input parameters for both the earth system and economic components of the IGSM.

The simulations of twentieth-century climate used to estimate uncertainties in the climate system parameters (Forest et al. 2006, 2008) were carried out using both anthropogenic and natural forcings. As discussed by Forest et al. (2006), taking into account natural forcings, especially forcing due to volcanic eruptions, led to significantly different distributions of climate system parameters compared to the distributions based on twentieth-century simulations with just anthropogenic forcings (Forest et al. 2002), which was used by Webster et al. (2003). The main consequence of the changes in the climate input distributions is an increase in the lower bound of the distribution of surface warming in response to an external forcing.

Similarly, the distributions of global GHGs emissions used in this study (Webster et al. 2008) are higher, compared with previous results (Webster et al. 2002) because of the reduction of very low emissions growth cases. One of the key differences is that GDP growth, while still more important than many other parameters, is not the primary driver of uncertainty in emissions. This change is a result of the new approach of generating GDP growth paths using a random walk and of the assumption that GDP growth shocks are not correlated across countries. From this analysis, the primary drivers of uncertainty in no-policy carbon emissions are technological change, both price driven (e.g., elasticity of substitution) and nonprice driven (e.g., autonomous energy efficiency improvement), and the total fossil resources available, particularly coal and shale (Webster et al. 2008). These changes in projected GHGs emissions noticeably decreased the probability of low radiative forcing.

Because of the multiplicative nature of the interaction between the forcing and the climate system response, the probability distribution of the increase in surface air temperature at the end of the twenty-first century is shifted upward significantly compared to the distribution obtained by Webster et al. (2003). As can be expected from the changes in the forcing and the response described above, the biggest difference is a sharp decrease in the probability of small or moderate warming. While the upper bound of the $90 \%$ range has increased by about $60 \%$, the lower bound of the $90 \%$ range of the new distribution is more than 3 times larger than in the Webster et al. (2003).

While our median anthropogenic emissions are similar to those for the SRES A2 scenario, the GHGs concentrations simulated by the MIT IGSM are somewhat higher than those used in the simulations with the IPCC AR4 AOGCMs. These differences in GHG concentrations arise from the different treatment of the terrestrial ecosystem and from the fact that we take into account an increase in the natural $\mathrm{CH}_{4}$ and $\mathrm{N}_{2} \mathrm{O}$ emissions caused by the surface warming, as well as from differences in chemistry models (Prinn et al. 2008). As a result, the total radiative forcing in our simulations with median anthropogenic emissions is quite close to the forcing for the IPCC A1FI scenario. However, the surface warming projected by the MIT IGSM significantly exceeds the

TABLE 5. Ratios of the percentiles values to the means for probability distributions shown in Table 4.

\begin{tabular}{|c|c|c|c|c|}
\hline & $5 \%$ & $16.7 \%$ & $83.3 \%$ & $95 \%$ \\
\hline MIT simulations with median anthropogenic emissions & 0.74 & 0.82 & 1.17 & 1.35 \\
\hline $\begin{array}{l}\text { SCM MAGICC6 Meinshausen et al. (2008) } \\
\text { (with uncertainty in feedback between climate and carbon cycle) for SRES A1FI }\end{array}$ & 0.70 & 0.80 & 1.17 & 1.44 \\
\hline SCM MAGICC4 (with carbon uptake uncertainty) for SRES A1FI & - & 0.77 & 1.35 & - \\
\hline IPCC AR4 for SRES A1FI & \multicolumn{2}{|c|}{0.60} & \multicolumn{2}{|c|}{1.60} \\
\hline
\end{tabular}


TABLE 6. Distributions for changes in SAT at the last decade of the twenty-first century for different choices of climate parameters distributions.

\begin{tabular}{clccccc}
\hline \hline & & $5 \%$ & $16.7 \%$ & Mean & $83.3 \%$ & $95 \%$ \\
\hline Full uncertainties & LEV05 & 3.50 & 4.12 & 5.28 & 6.42 & 7.37 \\
& NO & 3.30 & 3.88 & 4.96 & 6.04 & 6.93 \\
& DOM08 & 2.70 & 3.17 & 4.06 & 4.94 & 5.67 \\
Climate-only & LEV05 & 3.81 & 4.22 & 5.17 & 6.04 & 6.98 \\
uncertainties & NO & 3.58 & 3.97 & 4.87 & 5.68 & 6.57 \\
& DOM08 & 2.93 & 3.25 & 3.98 & 4.65 & 5.38 \\
\hline
\end{tabular}

estimates given by Meehl et al. (2007a). The shape of the probability distribution of changes in SAT simulated by the MIT IGSM is also different from those assumed by the IPCC AR4 or obtained in simulations with the SCM MAGICC. The distribution obtained in our simulations is more symmetric. Asymmetry in the IPCC and MAGICC distributions is, in part, explained by the larger impact of the uncertainty in the feedback between the climate and the carbon cycle on the upper bound of the surface warming range. Taking into consideration the interaction between carbon and nitrogen in the terrestrial ecosystem model reduces the strength of this feedback and the uncertainty in surface warming associated with it (Sokolov et al. 2008).

All the ensembles of simulations presented in this paper were carried out with climate input parameter distributions based on the Levitus et al. (2005) estimate of changes in the deep-ocean heat content. We also derived approximate distributions of changes in SAT for climate parameter distributions based on alternate estimates of the ocean heat uptake. These estimates suggest somewhat smaller surface warming. However, the probability of the SAT increase at the end of the twentyfirst century being near $2^{\circ}-2.5^{\circ} \mathrm{C}$ is still significantly lower than that suggested by the IPCC AR4 for all the distributions tested. As noted in the introduction, the sensitivity of our results to other assumptions was not tested in this study.

Acknowledgments. We would to thank Malte Meinshausen for providing results of the simulations with SCM MAGICC version 6 and Reto Knutii for useful discussion of SCM results. We also thank Mat Collins and an anonymous reviewer for their comments and suggestions. This work was supported in part by the Office of Science (BER), U.S. Department of Energy Grants DE-FG02-94ER61937 and DE-FG02-93ER61677, and by the industrial and foundations sponsors of The MIT Joint Program on the Science and Policy of Global Change (http://globalchange.mit.edu/sponsors/ current.html). We thank Josh Willis for discussions on the ocean heat content data. We acknowledge the modeling groups, the Program for Climate Model Diagnosis and Intercomparison (PCMDI) and the WCRP's Working Group on Coupled Modelling (WGCM) for their roles in making available the WCRP CMIP3 multimodel dataset. Support of this dataset is provided by the Office of Science, U.S. Department of Energy.

\section{REFERENCES}

Babiker, M. H., J. M. Reilly, M. Mayer, R. S. Eckaus, I. S. Wing, and R. C. Hyman, 2001: The MIT Emissions Prediction and Policy Analysis (EPPA) Model: Revisions, sensitivities, and comparisons of results. MIT Joint Program on the Science and Policy of Global Change, Rep. 71, 90 pp. [Available online at http://web.mit.edu/globalchange/www/MITJPSPGC_Rpt71.pdf.] , G. E. Metcalf, and J. Reilly, 2003: Tax distortions and global climate policy. J. Environ. Econ. Manage., 46, 269-287.

Bonan, G. B., K. W. Oleson, M. Vertenstein, S. Lewis, X. Zeng, Y. Dai, R. E. Dickinson, and Z.-L. Yang, 2002: The land surface climatology of the Community Land Model coupled to the NCAR Community Climate Model. J. Climate, 15, 3123-3149.

Calbó, J., W. Pan, M. Webster, R. G. Prinn, and G. J. McRae, 1998: Parameterization of urban subgrid-scale processes in global atmospheric chemistry models. J. Geophys. Res., 103, 3437-3451.

Clarke, L. E., J. A. Edmonds, H. D. Jacoby, H. M. Pitcher, J. M. Reilly, and R. G. Richels, 2007: CCSP Synthesis and Assessment Product 2.1, Part A: Scenarios of Greenhouse Gas Emissions and Atmospheric Concentrations, U.S. Climate Change Science Program, Department of Energy, Washington, DC, 154 pp.

Curtis, P. S., and X. Wang, 1998: A meta-analysis of elevated $\mathrm{CO}_{2}$ effects on woody plant mass, form, and physiology. Oecologia, 113, 299-313.

Dalan, F., P. H. Stone, I. Kamenkovich, and J. Scott, 2005a: Sensitivity of the ocean's climate to diapycnal diffusivity in EMIC. Part I: Equilibrium state. J. Climate, 18, 2460-2481.

$\longrightarrow,-$, and A. P. Sokolov, 2005b: Sensitivity of the ocean's climate to diapycnal diffusivity in EMIC. Part II: Global warming scenario. J. Climate, 18, 2482-2496.

Dimaranan, B., and R. McDougall, cited 2002: Global trade, assistance, and production: The GTAP 5 data base. Center for Global Trade Analysis, Purdue University, West Lafayette, IN. [Available online at https://www.gtap.agecon.purdue.edu/ databases/v5/v5_doco.asp.]

Dirmeyer, P. A., X. Gao, and T. Oki, 2002: The Second Global Soil Wetness Project (GSWP2). International GEWEX Project Office Publication 37, 75 pp.

Domingues, C. M., J. A. Church, N. J. White, P. J. Gleckler, S. E. Wijffels, P. M. Barker, and J. R. Dunn, 2008: Improved estimates of upper-ocean warming and multi-decadal sea-level rise. Nature, 453, 1090-1094.

Edmonds, J. A., and J. M. Reilly, 1985: Future global energy and carbon dioxide emissions. Atmospheric carbon dioxide and the global carbon cycle, DOE/ER-0239, U.S. Department of Energy, Office of Energy Research, Washington, DC, 215-246.

Felzer, B., D. W. Kicklighter, J. M. Melillo, C. Wang, Q. Zhuang, and R. Prinn, 2004: Effects of ozone on net primary production and carbon sequestration in the conterminous United States using a biogeochemistry model. Tellus, 56B, 230-248.

Follows, M. J., T. Ito, and S. Dutkiewicz, 2006: A compact and accurate carbonate chemistry solver for ocean biogeochemistry models. Ocean Modell., 12, 290-301. 
Forest, C. E., P. H. Stone, A. P. Sokolov, M. R. Allen, and M. Webster, 2002: Quantifying uncertainties in climate system properties with the use of recent climate observations. Science, 295, 113-117.

,$- \ldots$, and — 2006: Estimated PDFs of climate system properties including natural and anthropogenic forcings. Geophys. Res. Lett., 33, L01705, doi:10.1029/2005GL023977.

,-- , and,- 2008 : Constraining climate model parameters from observed 20th century changes. Tellus, 60A, 911-920.

Friedlingstein, P., and Coauthors, 2006: Climate-carbon cycle feedback analysis: Results from the $\mathrm{C}^{4} \mathrm{MIP}$ model intercomparison. J. Climate, 19, 3337-3353.

Gouretski, V., and K. P. Koltermann, 2007: How much is the ocean really warming? Geophys. Res. Lett., 34, L01610, doi:10.1029/ 2006 GL027834.

Gunderson, C. A., and S. D. Wullschleger, 1994: Photosynthetic acclimation in trees to rising atmospheric $\mathrm{CO}_{2}$ : $\mathrm{A}$ broader perspective. Photosynth. Res., 39, 369-388.

Hansen, J., G. Russell, D. Rind, P. Stone, A. Lacis, S. Lebedeff, R. Ruedy, and L. Travis, 1983: Efficient three-dimensional global models for climate studies: Models I and II. Mon. Wea. Rev., 111, 609-662.

, A. Lacis, D. Rind, G. Russell, P. Stone, I. Fung, R. Ruedy, and J. Lerner, 1984: Climate sensitivity: Analysis of feedback mechanisms. Climate Processes and Climate Sensitivity, Geophys. Monogr., Vol. 29, Amer. Geophys. Union, 130-163.

- I. Fung, A. Lacis, D. Rind, S. Lebedeff, R. Ruedy, and G. Russell, 1988: Global climate change as forecast by Goddard Institute for Space Studies three-dimensional model. J. Geophys. Res., 93, 9341-9364.

— , and Coauthors, 2002: Climate forcings in Goddard Institute for Space Studies SI2000 simulations. J. Geophys. Res., 107, 4347, doi:10.1029/2001JD001143.

Hegerl, G. C., and Coauthors, 2007: Understanding and attributing climate change. Climate Change 2007: The Physical Science Basis, S. Solomon et al. Eds., Cambridge University Press, 663-745.

Holian, G. L., A. P. Sokolov, and R. G. Prinn, 2001: Uncertainty in atmospheric $\mathrm{CO}_{2}$ predictions from a global ocean carbon cycle model. MIT Joint Program on the Science and Policy of Global Change Report 80, Rep. 80, 25 pp. [Available online at http://web.mit.edu/globalchange/www/MITJPSPGC_Rpt80.pdf.]

Houghton, J. T., Y. Ding, D. J. Griggs, M. Noguer, P. J. van der Linden, X. Dai, K. Maskell, and C. A. Johnson, 2001: Climate Change 2001: The Scientific Basis. Cambridge University Press, 881 pp.

Iman, R. L., and W. J. Conover, 1982: A distribution-free approach to inducing rank correlation among input variables. Commun. Stat. Simul. Comput., 11, 311-334.

— sensitivity analysis techniques for computer models. Risk Anal., 8, 71-90.

Jacoby, H., R. Eckaus, A. D. Ellermann, R. Prinn, D. Reiner, and Z. Yang, 1997: $\mathrm{CO}_{2}$ emissions limits: Economic adjustments and the distribution of burdens. Energy J., 18, 31-58.

Kamenkovich, I. V., A. Sokolov, and P. H. Stone, 2002: An efficient climate model with a 3D ocean and statistical-dynamical atmosphere. Climate Dyn., 19, 585-598.

Knutti, R., T. F. Stoker, F. Joos, and G.-K. Plattner, 2003: Probabilistic climate change projections using neural network. Climate Dyn., 21, 257-272.

, and Coauthors, 2008: A review of uncertainties in global temperature projections over the twenty-first century. J. Climate, 21, 2651-2663.
Lean, J., 2000: Evolution of the sun's spectral irradiance since the Maunder Minimum. Geophys. Res. Lett., 27, 2421-2424.

Levitus, S., J. Antonov, and T. P. Boyer, 2005: Warming of the World Ocean, 1955-2003. Geophys. Res. Lett., 32, L02604, doi:10.1029/2004GL021592.

Li, C., S. Frolking, and T. A. Frolking, 1992: A model of nitrous oxide evolution from soil driven by rainfall events: 1 . Model structure and sensitivity. J. Geophys. Res., 97, 9759-9776.

Liu, Y., 1996: Modeling the emissions of nitrous oxide $\left(\mathrm{N}_{2} \mathrm{O}\right)$ and methane $\left(\mathrm{CH}_{4}\right)$ from the terrestrial biosphere to the atmosphere. Ph.D. thesis, MIT Joint Program on the Science and Policy of Global Change, Rep. 10, 219 pp. [Available online at http:// globalchange.mit.edu/files/document/MITJPSPGC_Report10. pdf.]

Mayer, M., C. Wang, M. Webster, and R. G. Prinn, 2000: Linking local air pollution to global chemistry and climate. J. Geophys. Res., 105, 22 869-22 896.

McGuire, A. D., J. M. Melillo, L. A. Joyce, D. W. Kicklighter, A. L. Grace, B. Moore III, and C. J. Vorosmarty, 1992: Interactions between carbon and nitrogen dynamics in estimating net primary productivity for potential vegetation in North America. Global Biogeochem. Cycles, 6, 101-124.

—, L. A. Joyce, D. W. Kicklighter, J. M. Melillo, G. Esser, and C. J. Vorosmarty, 1993: Productivity response of climax temperate forests to elevated temperature and carbon dioxide: A North American comparison between two global models. Climatic Change, 24, 287-310.

_ - and Coauthors, 1997: Equilibrium responses of global net primary production and carbon storage to doubled atmospheric carbon dioxide: Sensitivity to changes in vegetation nitrogen concentration. Global Biogeochem. Cycles, 11, 173-189.

Meehl, G. A., and Coauthors, 2007a: Global climate projections. Climate Change 2007: The Physical Science Basis, S. Solomon et al., Eds., Cambridge University Press, 746-845. , C. Covey, T. Delworth, M. Latif, B. McAvaney, J. F. B. Mitchell, R. J. Stouffer, and K. E. Taylor, 2007b: The WCRP CMIP3 multimodel dataset: A new era in climate change research. Bull. Amer. Meteor. Soc., 88, 1383-1394.

Meinshausen, M., S. C. B. Raper, and T. M. L. Wigley, 2008: Emulating IPCC AR4 atmosphere-ocean and carbon cycle models for projecting global-mean, hemispheric and land/ ocean temperatures: MAGICC 6.0. Atmos. Chem. Phys. Discuss., 8, 6153-6272.

Melillo, J. M., A. D. McGuire, D. W. Kicklighter, B. Moore III, C. J. Vorosmarty, and A. L. Schloss, 1993: Global climate change and terrestrial net primary production. Nature, 363, 234-240.

Morgan, M. G., and D. Keith, 1995: Subjective judgments by climate experts. Environ. Sci. Technol., 29, 468-476.

Moss, R. H., and S. H. Schneider, 2000: Towards consistent assessment and reporting of uncertainties in the IPCC TAR. Cross-Cutting Issues in the IPCC Third Assessment Report, R. Pachauri and T. Taniguchi, Eds., Cambridge University Press, 35-51.

Nakicenovic, N., and Coauthors, 2000: Intergovernmental Panel on Climate Change Special Report on Emission Scenarios. Cambridge University Press, $570 \mathrm{pp}$.

Norby, R. J., and Coauthors, 2005: Forest response to elevated $\mathrm{CO}_{2}$ is conserved across a broad range of productivity. Proc. Natl. Acad. Sci. USA, 102, 18 052-18 056.

Nordhaus, W. D., and G. W. Yohe, 1983: Future paths of energy and carbon dioxide emissions. Changing Climate, Report of the Carbon Dioxide Assessment Committee of the National Academy of Science, National Academies Press, 87-152. 
Olivier, J. G. J., and J. J. M. Berdowski, 2001: Global emission sources and sinks. The Climate System, J. Berdowski, R. Guicherit, and B. J. Heij, Eds., Swets and Zeitlinger, 33-77.

Paltsev, S., J. M. Reilly, H. D. Jacoby, R. S. Eckaus, J. McFarland, M. Sarofim, M. Asadoorian, and M. Babiker, 2005: The MIT Emissions Prediction and Policy Analysis (EPPA) Model: Version 4. MIT Joint Program for the Science and Policy of Global Change, Rep. 125, 72 pp. [Available online at http:// web.mit.edu/globalchange/www/MITJPSPGC_Rpt125.pdf.]

,,,--- A. Gurgel, G. Metcalf, A. Sokolov, and J. Holak, 2008: Assessment of U.S. GHG cap-and-trade proposals. Climate Policy, 8.4, 395-420.

Pan, Y., and Coauthors, 1998: Modeled responses of terrestrial ecosystems to elevated atmospheric $\mathrm{CO}_{2}$ : A comparison of simulations by the biogeochemistry models of the Vegetation/ Ecosystem Modeling and Analysis Project (VEMAP). Oecologia, 114, 389-404.

Peixoto, J. P., and A. H. Oort, 1992: Physics of Climate. AIP, 520 pp.

Plattner, G.-K., and Coauthors, 2008: Long-term climate commitments projected with climate-carbon cycle models. J. Climate, 21, 2721-2751.

Prinn, R., and Coauthors, 1999: Integrated global system model for climate policy assessment: Feedbacks and sensitivity studies. Climatic Change, 41, 469-546.

_ - J. Reilly, M. Sarofim, C. Wang, and B. Felzer, 2007: Effects of air pollution control on climate: results from an integrated assessment model. Human-Induced Climate Change: An Interdisciplinary Assessment, M. E. Schlesinger et al., Eds., Cambridge University Press, 93-102.

_ S. Paltsev, A. Sokolov, M. Sarofim, J. Reilly, and H. Jacoby, 2008: The influence on climate change of differing scenarios for future development analyzed using the MIT Integrated Global System Model. MIT Joint Program for the Science and Policy of Global Change, Rep. 163, 28 pp. [Available online at http:// web.mit.edu/globalchange/www/MITJPSPGC_Rpt163.pdf.]

Raich, J. W., and Coauthors, 1991: Potential net primary productivity in South America: Application of a global model. Ecol. Appl., 1, 399-429.

Reilly, J., and S. Paltsev, 2006: European greenhouse gas emissions trading: A system in transition. Economic Modeling of Climate Change and Energy Policies, M. De Miguel et al., Eds., Edward Elgar Publishing, 45-64.

— J. Edmonds, R. Gardner, and A. Brenkert, 1987: Monte Carlo analysis of the IEA/ORAU energy/carbon emissions model. Energy J., 8 (3), 1-29.

_ , and Coauthors, 1999: Multi-gas assessment of the Kyoto Protocol. Nature, 401, 549-555.

Russell, G. L., J. R. Miller, and L.-C. Tsang, 1985: Seasonal ocean heat transport computed from an atmospheric model. Dyn Atmos. Oceans, 9, 253-271.

Sato, M., J. E. Hansen, M. P. McCormick, and J. B. Pollack, 1993: Stratospheric aerosol optical depths. J. Geophys. Res., 98, 22 987-22 994.

Schlosser, C. A., D. Kicklighter, and A. Sokolov, 2007: A global land system framework for integrated climate-change assessments. MIT Joint Program for the Science and Policy of Global Change, Rep. 147, 82 pp. [Available on line at http:// web.mit.edu/globalchange/www/MITJPSPGC_Rpt147.pdf.]

Smith, S. J., R. Andres, E. Conception, and J. Lurz, 2004: Historical sulfur dioxide emissions 1850-2000: Methods and results. PNNL Research Rep. 14537, Pacific Northwest National Laboratory, $16 \mathrm{pp}$.
Sokolov, A. P., 2006: Does model sensitivity to changes in $\mathrm{CO}_{2}$ provide a measure of sensitivity to other forcings? J. Climate, 19, 3294-3306.

- and P. H. Stone, 1998: A flexible climate model for use in integrated assessments. Climate Dyn., 14, 291-303.

C. Wang, G. Holian, P. H. Stone, and R. Prinn, 1998: Uncertainty in the oceanic heat and carbon uptake and their impact on climate projections. Geophys. Res. Lett., 25, 3603-3606.

— , and Coauthors, 2005: The MIT Integrated Global System Model (IGSM) Version 2: Model description and baseline evaluation. MIT Joint Program for the Science and Policy of Global Change, Rep. 124, 40 pp. [Available online at http:// web.mit.edu/globalchange/www/MITJPSPGC_Rpt124.pdf.]

, S. Dutkiewicz, P. H. Stone, and J. R. Scott, 2007: Evaluating the use of ocean models of different complexity in climate change studies. MIT Joint Program for the Science and Policy of Global Change, Rep. 128, 23 pp. [Available online at http:// web.mit.edu/globalchange/www/MITJPSPGC_Rpt128.pdf.]

— D. W. Kicklighter, J. M. Melillo, B. Felzer, C. A. Schlosser, and T. W. Cronin, 2008: Consequences of considering carbonnitrogen interactions on the feedbacks between climate and the terrestrial carbon cycle. J. Climate, 21, 3776-3796.

C. E. Forest, and P. H. Stone, 2009: Sensitivity of climate change projections to uncertainties in the estimates of observed changes in deep-ocean heat content. Climate Dyn., in press.

Solomon, S., D. Qin, M. Manning, M. Marquis, K. Averyt, M. M. B. Tignor, H. L. Miller Jr., and Z. Chen, 2007: Climate Change 2007: The Physical Science Basis. Cambridge University Press, $996 \mathrm{pp}$.

Stern, D. I., 2005: Beyond the environmental Kuznets curve: Diffusion of sulfur-emissions-abating technology. J. Environ. Dev., 14, 101-124.

2006: Reversal of the trend in global anthropogenic sulfur emissions. Global Environ. Change, 16, 207-220.

Stocker, T. F., W. S. Broecker, and D. G. Wright, 1994: Carbon uptake experiments with a zonally-averaged global ocean circulation model. Tellus, 46B, 103-122.

Stone, P. H., and M.-S. Yao, 1987: Development of a twodimensional zonally averaged statistical-dynamical model. Part II: The role of eddy momentum fluxes in the general circulation and their parameterization. J. Atmos. Sci., 44, 3769-3786. , and — 1990: Development of a two-dimensional zonally averaged statistical-dynamical model. Part III: The parameterization of the eddy fluxes of heat and moisture. J. Climate, $\mathbf{3}$, 726-740

Tatang, M. A., W. Pan, R. G. Prinn, and G. J. McRae, 1997: An efficient method for parametric uncertainty analysis of numerical geophysical models. J. Geophys. Res., 102, 21 925-21 932.

Wang, C., 2004: A modeling study on the climate impacts of black carbon aerosols. J. Geophys. Res., 109, D03106, doi:10.1029/ 2003JD004084.

R. G. Prinn, and A. Sokolov, 1998: A global interactive chemistry and climate model: Formulation and testing. J. Geophys. Res., 103, 3399-3418.

Wang, Y., and D. Jacob, 1998: Anthropogenic forcing on tropospheric ozone and $\mathrm{OH}$ since preindustrial times. J. Geophys. Res., 103, 31 123-31 135.

Webster, M. D., and A. P. Sokolov, 2000: A methodology for quantifying uncertainty in climate projections. Climatic Change, 46, 417-446.

, M. Babiker, M. Mayer, J. M. Reilly, J. Harnisch, R. Hyman, M. C. Sarofim, and C. Wang, 2002: Uncertainty in emissions projections for climate models. Atmos. Environ., 36, 3659-3670. 
and Coauthors, 2003: Uncertainty analysis of climate change and policy response. Climatic Change, 62, 295-320.

, S. Paltsev, J. Parsons, J. Reilly, and H. Jacoby, 2008: Uncertainty in greenhouse emissions and costs of atmospheric stabilization. MIT Joint Program for the Science and Policy of Global Change, Rep. 165, 28 pp. [Available online at http:// globalchange.mit.edu/files/document/MITJPSPGC_Rpt165.pdf.]

Weyant, J. P., 2004: Introduction and overview. Energy Econ., 26, $501-515$

, and J. N. Hill, 1999: Introduction and overview. The Energy Journal Special Issue: The Costs of the Kyoto Protocol: A Multi-Model Evaluation, J. P. Weyant, Ed., IAEE, vii-xliv.
, F. de la Chesnaye, and G. Blanford, 2006: Overview of EMF-21: Multigas mitigation and climate policy. Energy J., 3, 1-32.

Wigley, T. M. L., and S. C. B. Raper, 2001: Interpretation of high projections for global-mean warming. Science, 293, 451-454.

Yao, M.-S., and P. H. Stone, 1987: Development of a twodimensional zonally averaged statistical-dynamical model. Part I: The parameterization of moist convection and its role in the general circulation. J. Atmos. Sci., 44, 65-82.

Zhuang, Q., and Coauthors, 2006: $\mathrm{CO}_{2}$ and $\mathrm{CH}_{4}$ exchanges between land ecosystems and the atmosphere in northern high latitudes over the 21st century. Geophys. Res. Lett., 33, L17403, doi:10.1029/2006GL026972. 


\title{
CORRIGENDUM
}

\author{
A. P. Sokolov, P. H. Stone, C. E. Forest, ${ }^{*}$ R. Prinn, M. C. Sarofim, ${ }^{+}$M. Webster, \# \\ S. PALtSEV, AND C. A. SChlosser \\ Joint Program on the Science and Policy of Global Change, Massachusetts \\ Institute of Technology, Cambridge, Massachusetts \\ D. KICKLIGHTER
}

The Ecosystems Center, Marine Biological Laboratory, Woods Hole, Massachusetts

S. DutKiewicz, J. ReILly, AND C. WANG

Joint Program on the Science and Policy of Global Change, Massachusetts Institute of Technology, Cambridge, Massachusetts

B. FELZER ${ }^{@}$ AND J. M. MELILlO

The Ecosystems Center, Marine Biological Laboratory, Woods Hole, Massachusetts

\author{
H. D. JACOBY
}

Joint Program on the Science and Policy of Global Change, Massachusetts Institute of Technology, Cambridge, Massachusetts

(Manuscript received 7 December 2009, in final form 11 December 2009)

The simulations with economic uncertainty discussed in section $4 \mathrm{~b}$ of Sokolov et al. (2009) were, by mistake, carried out with the mean values of the input climate parameters instead of the intended median values. While this mistake did not affect the resulting distributions of atmospheric $\mathrm{CO}_{2}$ and radiative forcing, it led to an upward shift in the distributions for the changes in surface air temperature (SAT) and sea level rise. Correct distributions are shown in Table 1 and in the revised version of Fig. 11. The ratios of the percentiles to the mean shown in Table 2 of Sokolov et al. (2009) did not change.

\section{REFERENCE}

Sokolov, A., and Coauthors, 2009: Probabilistic forecast for twenty-first-century climate based on uncertainties in emissions (without policy) and climate parameters. J. Climate, 22, 5175-5204.

* Current affiliation: Department of Meteorology, The Pennsylvania State University, University Park, Pennsylvania.

+ AAAS Science and Technology Policy Fellow, Washington, D.C.

\# Current affiliation: Engineering Systems Division, Massachusetts Institute of Technology, Cambridge, Massachusetts.

@ Current affiliation: Department of Earth and Environmental Sciences, Lehigh University, Bethlehem, Pennsylvania.

Corresponding author address: Andrei Sokolov, Joint Program on the Science and Policy of Global Change, Massachusetts Institute of Technology, 77 Massachusetts Ave., E40-431, Cambridge, MA 02139.

E-mail: sokolov@mit.edu 
TABLE 1. Percentiles for distributions of surface warming and sea level rise for the last decade of the twenty-first century in the ensembles with full, climate, and emission uncertainties.

\begin{tabular}{lccccc}
\hline \hline SAT & $5 \%$ & $16.7 \%$ & $50 \%$ & $83.3 \%$ & $95 \%$ \\
Full uncertainty & 3.50 & 4.12 & 5.12 & 6.42 & 7.37 \\
Emission uncertainty & 3.95 & 4.42 & 5.16 & 6.04 & 6.56 \\
Climate uncertainty & 3.81 & 4.22 & 5.12 & 6.04 & 6.98 \\
& & & & & \\
Sea level rise & $5 \%$ & $16.7 \%$ & $50 \%$ & $83.3 \%$ & $95 \%$ \\
Full uncertainty & 29 & 35 & 44 & 55 & 63 \\
Emission uncertainty & 36 & 39 & 44 & 49 & 52 \\
Climate uncertainty & 29 & 35 & 43 & 53 & 60 \\
\hline
\end{tabular}
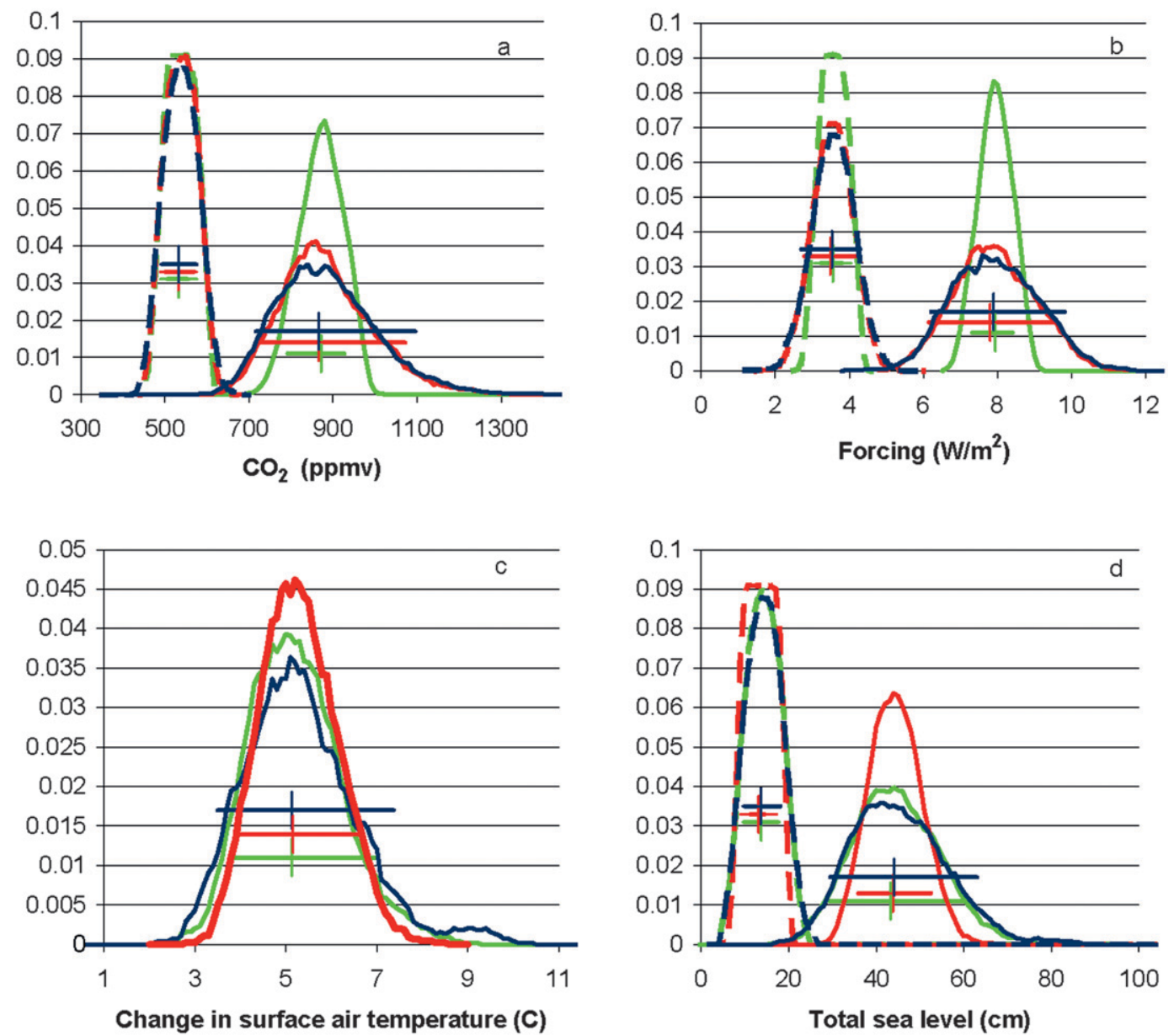

FIG. 11. Frequency distributions for (a) atmospheric $\mathrm{CO}_{2}$ concentrations, (b) radiative forcing due to greenhouse gases (GHGs) and sulfate aerosol, (c) surface air temperature, and (d) total sea level rise in simulations with full uncertainty (blue), climate uncertainty (green), and emissions uncertainty (red) averaged over 2041-50 (dashed lines) and 2091-2100 (solid lines). 